\title{
Financial uncertainty and interest rate movements: is Asian bond market volatility different?
}

\author{
Jungsuk Kim ${ }^{1}$ D $\cdot$ Abhishek Kumar ${ }^{2}$. Sushanta Mallick ${ }^{3}$. Donghyun Park ${ }^{4}$
}

Accepted: 30 August 2021

(c) The Author(s), under exclusive licence to Springer Science+Business Media, LLC, part of Springer Nature 2021

\begin{abstract}
The COVID-19 pandemic has given rise to a spike in financial market volatility. In this paper, we attempt to assess the effects of financial \& news-driven uncertainty shocks in growing Asian economies, using country-specific bond volatility shocks as a measure of local interest rate uncertainty. Also, we contrast the effects of local uncertainty with global stock market uncertainty. Using bond market data from nine Asian markets, we uncover a transmission mechanism of uncertainty shocks via the bond market. The mechanism works as a crowdingout effect due to government-led excessive market borrowing with supply-side consequences for the private sector, as opposed to economic policy or global stock market uncertainty which works more like a demand shock as in the literature. We conclude that countries with growing fiscal deficits that entail a larger government bond market or higher current account deficits, tend to experience an increase in the cost of borrowing due to this bond market volatility or interest rate uncertainty shocks.
\end{abstract}

Keywords Penalty function · Emerging Asia - Uncertainty · Bond market volatility · SVAR $\cdot$ Supply shock $\cdot$ Demand shock

JEL Classification E31 · E32 · E52 · E57

Jungsuk Kim

js_kim@sejong.ac.kr

Abhishek Kumar

abhishek@igidr.ac.in

Sushanta Mallick

s.k.mallick@qmul.ac.uk

Donghyun Park

dpark@adb.org

1 Sejong University, Seoul, South Korea

2 Indira Gandhi Institute of Development Research, Mumbai, India

3 Queen Mary University of London, London, UK

4 Asian Development Bank, Mandaluyong, Philippines 


\section{Introduction}

Following the global financial crisis of 2008-09, there has been a surge in the literature on uncertainty in macroeconomics research. The ongoing Covid-19 pandemic has made it even more important to understand the sources and transmission of uncertainty shocks. Elevated risk, reflected in equity market volatility, could prompt fears and delay investment in emerging economies, depressing stock prices (Caggiano et al. 2014; Bloom 2014). Bloom (2009) shows that any increase in uncertainty tends to freeze new hiring and investments by firms, affecting efficient resource allocation, causing significant output and employment losses in the short run. A pause in hiring and investment by firms is similar to the real options channel of Dixit et al. (1994). In times of high uncertainty, firms find it optimal to wait and see (Bernanke 1983). The real options channel implies that investment does not rise, despite falling interest rates due to a rise in precautionary savings during uncertain times.

Several authors have brought uncertainty in different ways into new Keynesian models to explore the transmission of uncertainty shocks to an economy. Ghironi and Ozhan (2020) explore interest rate uncertainty as a policy tool in an open economy New Keynesian model. According to them, the interest rate uncertainty can discourage short term capital flows and is likely to be inflationary due to higher mark-up. Our work is similar empirically to their theoretical work as we explore the transmission of interest rate uncertainty shock in nine Asian economies. There has been other studies exploring different kinds of uncertainties. In Christiano et al. (2014), entrepreneurs face uncertainty in converting capital to effective capital, and they view the magnitude of this uncertainty as risk. Their estimation suggests that the risk shock is the most important driver of US business cycles. Basu and Bundick (2017) brings uncertainty to the discount factor of households in a new Keynesian model, calling it a demand uncertainty. They show that the decline in output, hours, consumption, and investment in the model due to demand uncertainty shock is very similar to the VAR evidence on the effect of uncertainty shocks on the same variables.

In Bloom (2009), the real effect of uncertainty arises due to the expansion of inaction region as more firms wait and see. Traditionally, periods of uncertainty are expected to increase financial distortions and credit risk, harming investment. Gilchrist et al. (2014) bring these two channels in a general equilibrium model and show that both channels affect investment. Arellano et al. (2019) suggest that increased uncertainty induces firms to reduce their inputs to lower risk and this may exacerbate the wait and see problem. Baum et al. (2009) show that macroeconomic uncertainty reduces the optimal leverage for firms and investment may thus fall through this channel as well. In addition to existing firms reducing their investment, more firms are likely to fail during this time of high uncertainty, and thus exacerbate the real effects of uncertainty (see Byrne et al. 2016).

The leverage channel can also work through banks. Istiak and Serletis (2020) argue that during periods of high uncertainty, shadow banks reduce their leverage significantly. This is likely to cause disruptions in financial markets and credit flow to firms, leading to lower investment. Using a new Keynesian model, Leduc and Liu (2016) provide evidence that uncertainty shock is like a demand shock. Fasani and Rossi (2018) argue that the results in Leduc and Liu (2016) are driven by incorrect specification of the Taylor rule. Once the misspecification is corrected, uncertainty shock behaves like a supply shock. In other words, the specification of the Taylor rule turns out to be important for whether the uncertainty shock is a demand or supply shock in the new Keynesian model (also see Annicchiarico and Rossi 2015). 
It is not clear ex-ante whether these uncertainties are demand or supply shocks. The inference about supply and demand can be made after identifying the exogenous component of respective uncertainties and observing their transmission in the economy. If it moves inflation and output in the same direction, then it is a demand shock. On the other hand, if it moves inflation and output in opposite directions, then it is a supply shock. Any increase in global or domestic uncertainty can have a negative impact on the macro-economy; but the nature of the shock will determine its effects. Therefore, in this paper, we attempt to compare the transmission of financial uncertainty shocks in emerging Asian economies where business cycles and policy shocks behave differently, compared to a major economy, as discussed in Bhattarai et al. (2021). In our paper, we use Japan as a major regional economy for the purpose of comparison, and we make a distinction between bond market and equity market volatility shocks.

This paper attempts to compare bond volatility shock, which is a measure of interest rate uncertainty, with other measures of uncertainty commonly used in the literature such as VIX, VXO and EPU. Also, our choice of uncertainty implies that we are comparing equity market uncertainty with bond market uncertainty. The bond volatility and the newspaperbased economic policy uncertainty index (Baker et al. 2016) are country specific, whereas global uncertainty proxies namely VIX and VXO are common to all countries.

In this paper, we first identify uncertainty shock for all 9 Asian economies, using Cholesky decomposition and penalty function approaches. Our impulse response based identification (penalty function method) is related to Faust (1998), Uhlig (2005), Mountford and Uhlig (2009), Barsky and Sims (2011), Kurmann and Otrok (2013), and Caldara et al. (2016). Our penalty function identifies uncertainty shock as a shock that leads to four consecutive quarters of positive response in uncertainty and generates maximum increase in uncertainty over a period of one year.

We include bond market volatility as a measure of uncertainty. The uncertainty in the stock market is measured by the VIX and VXO index of implied volatility from options on S\&P 500 index. Our country specific VAR model is estimated from small sample and does not control for country heterogeneity. Therefore, we further estimate panel VAR and panel local projections which control for country heterogeneity. We identify uncertainty shocks and analyse responses due to these uncertainty shocks. Responses of model variables due to bond volatility, global VIX, VXO, and country specific economic policy uncertainty suggest that these shocks behave as demand shocks. Kumar et al. (2021) suggest that local uncertainty behaves as a supply shock in the case of India. Holtemoller and Mallick (2016) showed that inflation frequently originates as a supply shock in India unlike in advanced economies where inflation has primarily been a demand concern. Also, another important finding of the paper is that the interest rate uncertainty (bond volatility) shock increases interest rate (lending rate) unlike other measures of uncertainty shock. State dependent panel local projections suggest that the increase in interest rate due to an interest rate uncertainty shock is higher in countries with large public borrowing and current account deficit. A potential policy implication is that governments need to reduce their borrowing so as to lower the private sector's borrowing cost.

The rest of the paper is organized as follows. In Sect. 2, we describe the data and explain the construction of all the indices. In Sect. 3, we briefly explain the methodology and in Sect. 4 , we present the results. Section 5 concludes the paper. 


\section{Data}

In this section, we describe the data that we use in our empirical analysis. In addition, we explain different measures of financial uncertainty that are used in our analysis. We use data from the IMF and the Asian Development Bank's Asian Bonds Online portal (https://asianbondsonline.adb.org). Bond volatility data is provided for ten economies at Asian Bonds Online, a comprehensive source of information on emerging East Asian bond markets. The ten economies are: China (CHN), Hong Kong (HKG), Indonesia (IDN), Japan (JPN), Korea (KOR), Malaysia (MYS), Philippines (PHL), Singapore (SGP), Thailand (THL) and Vietnam (VNM). This data is available for all economies excluding China and Philippines from 2006:Q1. For China and Philippines, bond volatility is available from 2006:Q2 and 2007:Q2 respectively. Based on availability of other data, the sample for our country level estimation with bond volatility, VIX and VXO is as follows: CHN 2006:Q2-2019:Q3; HKG 2006:Q1-2019:Q3; IDN 2006:Q1-2019:Q3, JPN 2006:Q1-2019:Q3, KOR 2006:Q12019:Q3, MYS 2006:Q1-2018:Q4, PHL 2007:Q2-2019:Q2, SGP 2006:Q1-2019:Q3, THA 2006:Q1-2019:Q3. Our Panel VAR estimation requires a balanced sample and therefore we do the estimation for the time period 2007:Q2-2018:Q4. We follow the same sample for panel local projection. Our baseline estimation is done with lending rate and we conduct additional panel VAR estimations with monetary policy rate. Monetary policy rate does not have enough variability for China and Japan for longer time periods with many missing values. Therefore we drop China and Japan for our panel VAR estimation with monetary policy rate and one country-specific volatility, VIX and VXO.

These two other measures of financial uncertainty (international) are common across countries. First, we use a measure of global risk aversion via stock market uncertainty indexvolatility of VIX, which is a model-free volatility index that measures investor fear due to its negative relationship with S\&P 500 return dynamics, justifying its use as a proxy for market risk and volatility; second is volatility of VXO (CBOE S\&P 100 Volatility index is an estimate of the expected 30-day volatility of the S\&P 100 stock index), which is calculated using the same method as VIX. These two measures of uncertainty are available for longer duration, but we use them for the same time period for which data from Asian bond online is available for comparability.

Economic policy uncertainty (EPU) index is available for China, Hong Kong, Japan, Korea and Singapore. ${ }^{1}$ We use the values for EPU from all country level monthly data. We use the EPU index for Mainland China and the index for SCMP China for Hong Kong. There is another Hong Kong monthly index available on the website and also a hybrid China index which we do not use. EPU is available for the following time periods: China (1997:Q1), Hong Kong (1997:Q1), Japan (1987:Q1), Korea (1990:Q1) and Singapore (2003:Q1). Based on availability of other data, the sample for our country level estimation with EPU is as follows: CHN 2000:Q1-2019:Q3; HKG 1997:Q1-2019:Q3; JPN 1994:Q1-2017:Q1, KOR 1996:Q32019:Q3, SGP 2003:Q1-2019:Q3. To maintain comparability, our panel VAR estimations with EPU are done for the time period 2006:Q2-2017Q1. We follow the same sample for panel local projection. We do not do panel VAR and local projection with EPU and monetary policy rate, as after dropping China and Japan, we are left with only two countries.

The exchange rate used is a bilateral rate, defined as local currency per unit of USD. Increase in the exchange rate implies a depreciation of the local currency. We also use lending rate, gross domestic product (GDP) and consumer price index (CPI) for each country. We seasonally adjust GDP and CPI for each country separately. We use log of exchange rate,

$\overline{1}$ https://www.policyuncertainty.com/all_country_data.html. 

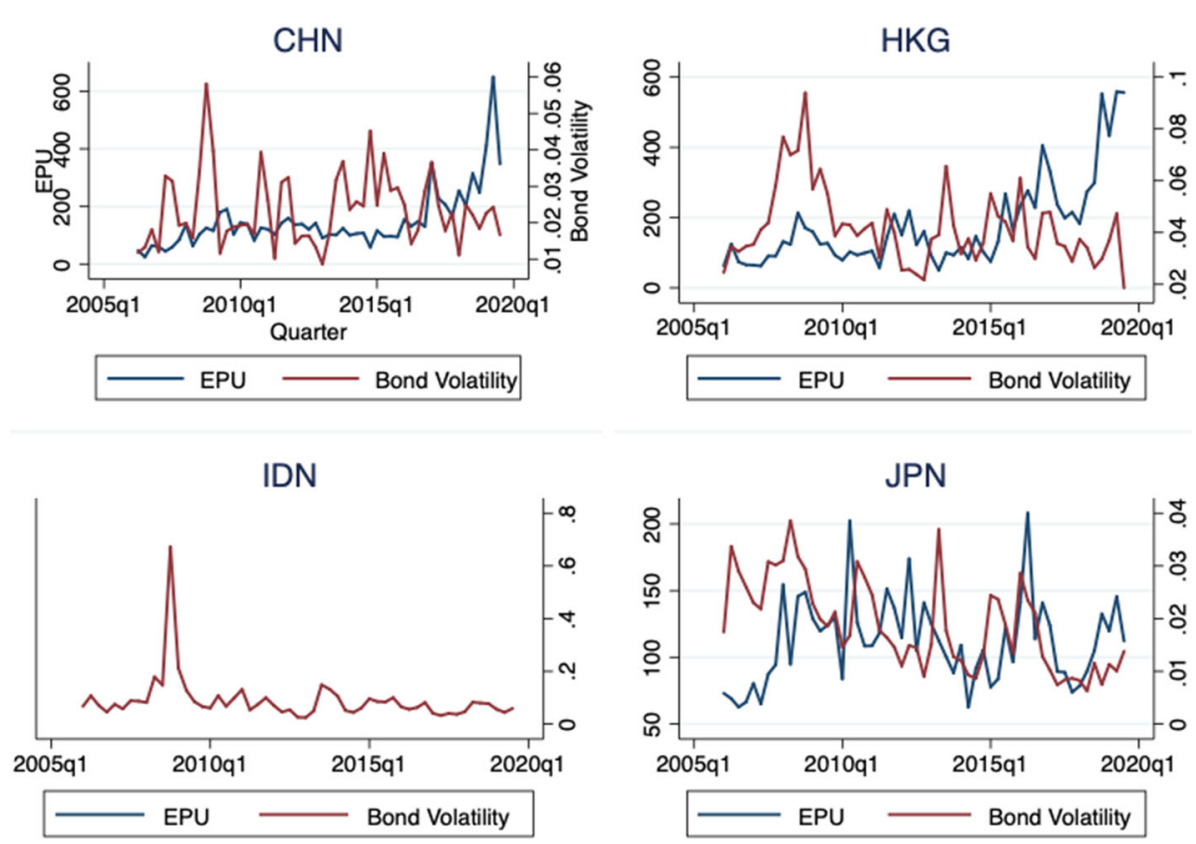

Fig. 1 Bond volatility and economic policy uncertainty Index

GDP, VIX, VXO, EPU and CPI. Since we do not find comparable data for other Asian countries, we drop them from the final analysis. Figures 1 and 2 give the bond volatility and economic policy uncertainty for the countries included in our sample. We also use annual data on current account balance, public and private bond market capitalization to estimate panel local projections. These models are estimated with the same set of 9 countries for the time period 2006-2017, depending upon the availability of data. In Table 5 in the Appendix, the summary statistics for the lending rate, the monetary policy rate and the exchange rate for each country are given. IDN has highest variability in the lending rate followed by PHL and KOR. HKG has highest variability in monetary policy rate follwed by IDN.

\section{Empirical framework}

In this section, we lay out the framework we use for our empirical analysis.

\subsection{Country specific VAR: Cholesky decomposition}

In general, the $k$ variate VAR model is given by a reduced form VAR model as:

$$
Y_{t}=B_{1} Y_{t-1}+B_{2} Y_{t-2}+\ldots .+B_{p} Y_{t-p}+u_{t}
$$

where $Y_{t}$ is a vector of variables and $B_{i}$ are reduced form coefficients. Also we have $E\left(u_{t} u_{t}^{\prime}\right)=$ $\Sigma . p$ is the maximum lag used in the estimation. One can estimate the above system by OLS. The orthogonal impulse response is obtained using the Cholesky decomposition of $\Sigma$ using $B_{i}$. The variables used in the estimation are: uncertainty $\left(U_{i t}\right)$, exchange rate $\left(E R_{i t}\right)$, 


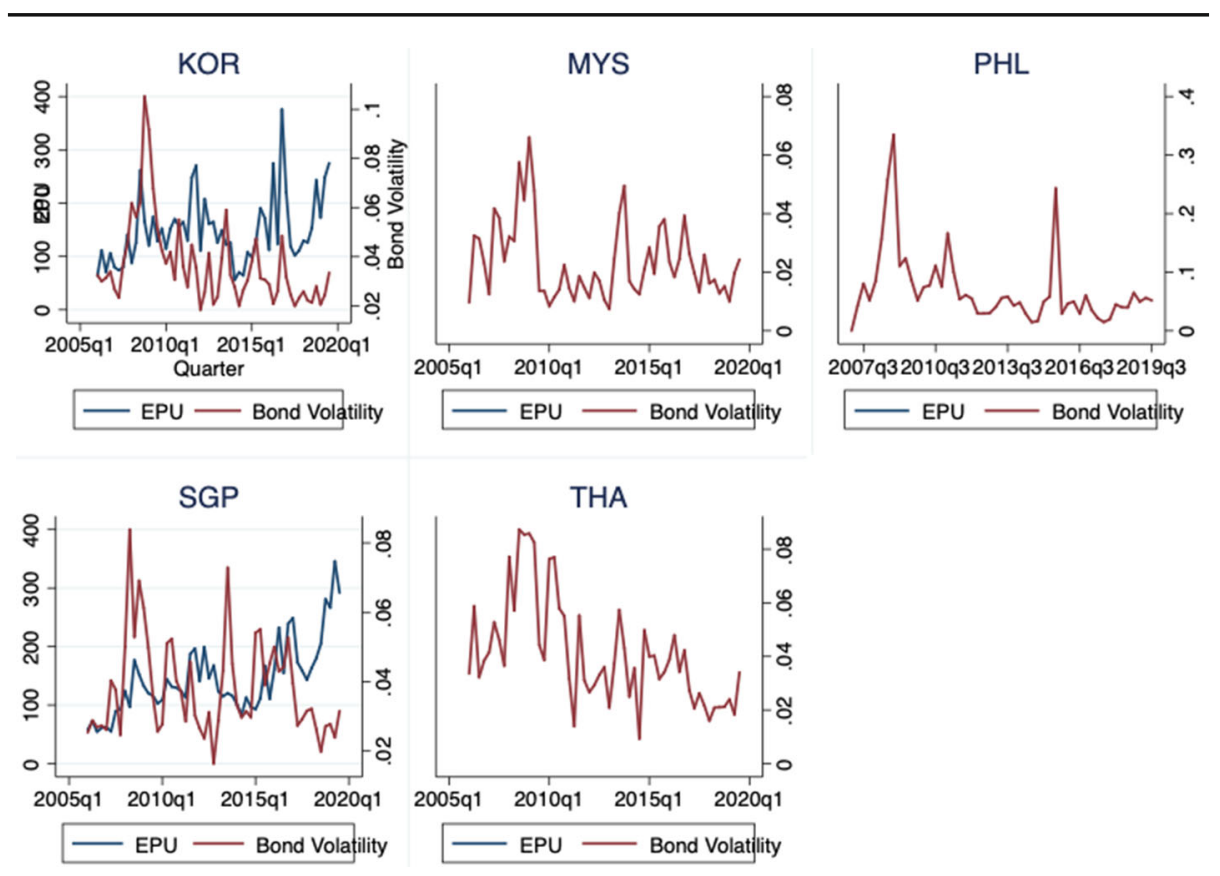

Fig. 2 Bond volatility and economic policy uncertainty Index

interest rate $\left(I R_{i t}\right)$, output $\left(G D P_{i t}\right)$ and consumer price index $\left(C P I_{i t}\right)$ in recursive order. We estimate the above VAR for 9 countries with bond volatility and 5 countries with EPU.

\subsection{Country specific VAR: Uhlig penalty function}

From the auto-regressive model given in (1), we write the moving average representation as follows:

$$
Y_{t}=C(L) u_{t}
$$

$u_{t}$ are reduced form shocks and are likely to be correlated. As they have very little economic meaning, we obtain Cholesky decomposition of the reduced form co-variance matrix: $\left(\sum=u_{t} u_{t}^{\prime}=A A^{\prime}\right)$ which implies a recursive ordering. One can assume structural shocks $\left(v_{t}\right)$ as uncorrelated, having unit variance. The reduced form shocks are linear combination of structural shocks and can be written as $u_{t}=A v_{t}$. The structural and reduced form variance co-variance matrices are related as:

$$
\sum=u_{t} u_{t}^{\prime}=A v_{t} v_{t} A^{\prime}=A A^{\prime}
$$

One can obtain the matrix $A$ using Cholesky decomposition and hence the structural moving average is given by:

$$
Y_{t}=C(L) A v_{t}
$$

The important point to note is that Cholesky decomposition is not the only possible decomposition of reduced form co-variance matrix. There are infinite number of decompositions possible. In general, one can assume an orthonormal matrix $Q$, and the above decomposition 
can be written as:

$$
\sum=A Q Q^{\prime} A^{\prime}=A A^{\prime}
$$

Now the structural shocks would be different and is given by $u_{t}=A Q \tilde{v}_{t}$. The corresponding structural moving average is given by:

$$
Y_{t}=C(L) A Q \tilde{v}_{t}
$$

We need to identify the matrix $Q$ for structural identification. In this paper, we identify selected columns of $Q$ given by $q_{j}=Q e_{j}$ where $e_{j}$ denotes the $j t h$ column of $I_{n}$. We define uncertainty shock as an innovation that generates the largest increase in a given measure of uncertainty for the first year i.e. four quarters. In the baseline case, we identify the uncertainty shock for all the countries separately and therefore we are identifying first column of $Q$. We put uncertainty as the first variable in the VAR for simplicity. The penalty function for the optimization problem is given by

$$
\Psi\left(q_{1}\right)=\sum_{l=0}^{3}-\frac{e_{1}^{\prime} C(L) A q_{1}}{\omega_{1}}
$$

with

$$
e_{1}^{\prime} C(L) A q_{1}>0 .
$$

The objective function is a penalty function that has to be minimized. The constraint ensures that the response of uncertainty due to the first shock is positive. We use uncertainty $\left(U_{i t}\right)$, exchange rate $\left(E R_{i t}\right)$, interest rate $\left(I R_{i t}\right)$, output $\left(G D P_{i t}\right)$ and consumer price index $\left(C P I_{i t}\right)$ in recursive order. We estimate the VAR for 9 countries with bond volatility, VIX, VXO and 5 countries with EPU.

\subsection{Panel VAR}

In general, the $k$ variate panel VAR model is given by

$$
\begin{aligned}
Y_{i t} & =u_{i}+A_{1} Y_{i t-1}+A_{2} Y_{i t-2}+\ldots+A_{p} Y_{i t-p}+\epsilon_{i t} \\
i & \in(1,2, \ldots, N), \quad t \in(1,2, \ldots, T)
\end{aligned}
$$

$Y_{i t}$ is $k \times 1$ vector of variables, $A_{i}$ is $k \times k$ coefficient matrices, $u_{i}$ is $k \times 1$ panel fixed effects. Also we have $E\left(\epsilon_{i t} \epsilon_{i t}^{\prime}\right)=\Sigma$. $p$ is the maximum lag used in the estimation. OLS estimation of the above system in the presence of lagged dependent variables on the right-hand side brings well known bias estimates which persist with large $N$ (Nickell 1981). Although the bias approaches zero as T gets larger, simulations by Judson and Owen (1999) find that the bias significantly decreases for $T>30$. We estimate the above system using panel fixed effect. $^{2}$ Once we have $A_{i}$, we make a companion form and the orthogonal impulse response is obtained using the Cholesky decomposition of $\Sigma$. Ordering of the variables in baseline panel VAR is as follows: uncertainty measure (bond volatility, VIX, VXO, EPU), exchange rate, lending rate, GDP and CPI. The same ordering is followed in panel VAR estimated with monetary policy rate and bond volatility. In the extended model, the ordering of the variables is used as follows: uncertainty measure (bond volatility), exchange rate, monetary policy rate, lending rate, GDP and CPI.

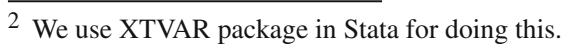




\subsection{Panel local projection}

We use a five variable structural system consisting of uncertainty $\left(U_{i t}\right)$, exchange rate $\left(E R_{i t}\right)$, interest rate $\left(I R_{i t}\right)$, output $\left(G D P_{i t}\right)$ and $\mathrm{CPI}\left(C P I_{i t}\right)$ in a recursive order.

$$
B Y_{i t}=u_{i}+A_{1} Y_{i t-1}+A_{2} Y_{i t-2}+\ldots+Y_{i t-p}+v_{i t}
$$

$k \times k$ matrix $B$ contains contemporaneous coefficients. It is a lower triangular matrix with 1 as diagonal elements by construction. The reduced form of the above is given by:

$$
Y_{i t}=B^{-1} u_{i}+B^{-1} A_{1} Y_{i t-1}+B^{-1} A_{2} Y_{i t-2}+\ldots+B^{-1} A_{p} Y_{i t-p}+B^{-1} v_{i t}
$$

which we can write as:

$$
Y_{i t}=B^{-1} u_{i}+C_{1} Y_{i t-1}+C_{2} Y_{i t-2}+\ldots+C_{p} Y_{i t-p}+u_{i t}
$$

The reduced form error $u_{i t}$ is related to the structural shock $v_{i t}$ as

$$
u_{i t}=B^{-1} v_{i t}
$$

The inverse of $B^{-1}$ is also a lower triangular matrix with 1 as diagonal elements and therefore the recursive system implies that structural shock associated with the first variable is same as the reduced form shock. Thus the structural shock associated with the uncertainty variable can be estimated by the equation given below.

$U_{i t}=\theta_{i}+C_{11} U_{i t-1}+C_{12} E R_{i t-1}+C_{13} I R_{i t-1}+C_{14} G D P_{i t-1}+C_{15} C P I_{i t-1}+v_{1, i t}$.

We are interested in the response of the other variables due to uncertainty shock and therefore we estimate the equation given below for $\left(E R_{i t}\right),\left(I R_{i t}\right),\left(G D P_{i t}\right)$ and $\left(C P I_{i t}\right)$

$P_{i t}=\theta_{i}+\phi_{0} U_{i t}+\phi_{1} U_{i t-1}+\phi_{2} E R_{i t-1}+\phi_{3} I R_{i t-1}+\phi_{4} G D P_{i t-1}+\phi_{4} C P I_{i t-1}+e_{i t}$

where $P_{i t}=\left(\left(E R_{i t}\right),\left(I R_{i t}\right),\left(G D P_{i t}\right),\left(C P I_{i t}\right)\right)$ one by one. Also $\phi_{i}$ may vary across equations. By Frisch-Waugh-Lovell (FWL) theorem, these above four regressions imply that the coefficient associated with $U_{i t}$ is basically the coefficient of structural shock associated with $U_{i t}$. One can therefore obtain the response of $P_{i t}$ due to a shock in $U_{i t}$ for several periods by doing the regression given below for $s=1,2, . ., h$.

$$
P_{i t+s}=\theta_{i}^{s}+\phi_{0}^{s} U_{i t}+\phi_{1}^{s} U_{i t-1}+\phi_{2}^{s} E R_{i t-1}+\phi_{3}^{s} I R_{i t-1}+\phi_{4}^{s} G D P_{i t-1}+\phi_{4}^{s} C P I_{i t-1}+e_{i t}
$$

By construction $\phi_{0}^{s}$ is the response at horizon $s=1,2, \ldots, h$ of $P_{i t}$ due to structural shock of $U_{i t}$. We use lag 1 as the estimation gives high $R^{2}$ with lag 1 . We use OLS, as $T$ is sufficiently greater than 30 and therefore we do not expect significant Nickel bias. We control for time trend in the above regression. We also estimate a model with annual data to assess the impact of uncertainty measure on the current account balance.

\subsection{State dependent panel local projection}

In this subsection, our objective is to explore the role of bond market capitalization and current account in transmission of the bond volatility shock to interest rate. We use public and private bond market capitalization data. Local projection used in the previous section is well suited 
Table 1 Response of model variables due to a bond volatility shock

\begin{tabular}{lllll}
\hline Country & Exchange rate & Interest rate & Gross domestic product & Consumer price index \\
\hline China & & - & & - \\
Hongkong & - & - & - & - \\
Indonesia & + & & - & \\
Japan & & - & - & + \\
Korea & + & - & - & - \\
Malaysia & + & + & - & - \\
Philippines & + & + & - & - \\
Singapore & & - & - &
\end{tabular}

"+" and "-" represent increases and decreases due to the shocks (in column). + for exchange rate implies depreciation. Insignificant responses are left blank. These are responses from country specific VAR estimated using Uhlig penalty function and Cholesky decomposition

Table 2 Response of model variables due to a VIX shock

\begin{tabular}{lllll}
\hline Country & Exchange rate & Interest rate & Gross domestic product & Consumer price index \\
\hline China & & - & & - \\
Hongkong & - & - & - & - \\
Indonesia & & - & + & + \\
Japan & - & & & + \\
Korea & + & - & - & - \\
Malaysia & & + & - & - \\
Philippines & + & - & - & \\
Singapore & & - & &
\end{tabular}

"+" and "-" represent increases and decreases due to the shocks in column. + for exchange rate implies depreciation. Insignificant responses are left blank. These are responses from country specific VAR estimated using Uhlig penalty function and Cholesky decomposition

Table 3 Response of model variables for a shock in VXO

\begin{tabular}{lllll}
\hline Country & Exchange rate & Interest rate & Gross domestic product & Consumer price index \\
\hline China & + & - & & - \\
Hongkong & - & - & - & - \\
Indonesia & & + & - & + \\
Japan & - & - & & + \\
Korea & + & - & - & - \\
Malaysia & & + & - & - \\
Phillipines & + & & - & - \\
Singapore & & - & - & \\
Thailand & & & &
\end{tabular}

"+" and "-" represent increases and decreases due to the shocks in columns. + for exchange rate implies depreciation. Insignificant responses are left blank. These are responses from country specific VAR estimated using Uhlig penalty function and Cholesky decomposition 
Table 4 Response of model variables due to EPU shock

\begin{tabular}{lllll}
\hline Country & Exchange rate & Interest rate & Gross domestic product & Consumer price index \\
\hline China & & & & - \\
Hongkong & + & - & - & - \\
Japan & - & - & - & \\
Korea & + & - & + \\
Singapore & & - &
\end{tabular}

"+" and "-" represent increases and decreases due to the shocks in columns. + for exchange rate implies depreciation. Insignificant responses are left blank. These are responses from country specific VAR estimated using Uhlig penalty function and Cholesky decomposition

(a) GDP

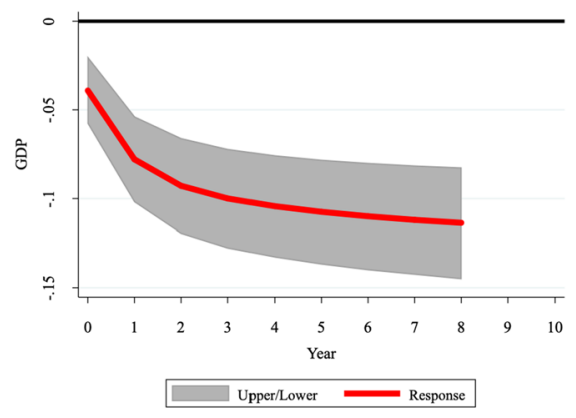

(c) IR

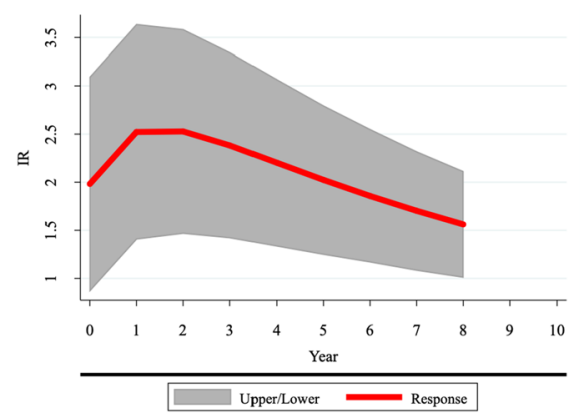

(b) CPI

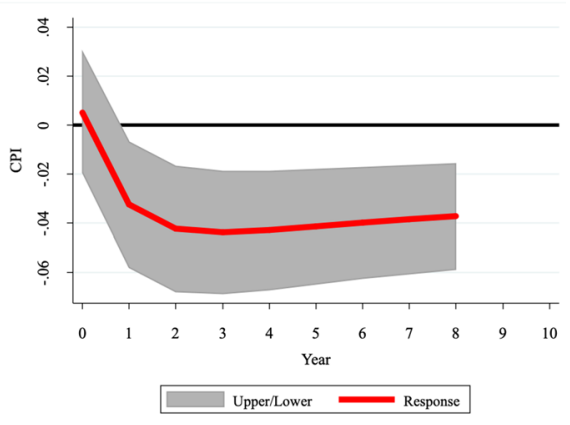

(d) $\mathrm{ER}$

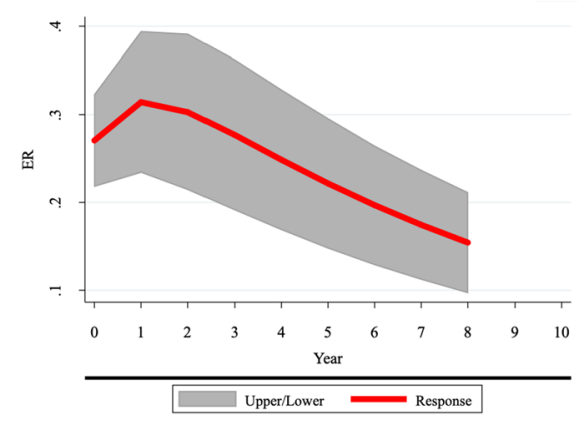

Fig. 3 Response of model variables to a bond volatility shock. Shaded region is $68 \%$ confidence band for the same. IR is lending rate. These are responses obtained from Panel VAR with country fixed effects

for bringing non-linearity and state dependence in responses. We include an interaction of bond volatility and bond market capitalization in our local projection regression.

$$
\begin{aligned}
I R_{i t+s}= & \theta_{i}^{s}+\beta_{0}^{s} U_{i t} \times B M C+\phi_{0}^{s} U_{i t}+\phi_{1}^{s} U_{i t-1}+\phi_{2}^{s} E R_{i t-1}+\phi_{3}^{s} I R_{i t-1} \\
& +\phi_{4}^{s} G D P_{i t-1}+\phi_{4}^{s} C P I_{i t-1}+e_{i t}
\end{aligned}
$$

where $\mathrm{BMC}$ is bond market capitalization. The coefficient of interest is $\beta_{0}$. Positive value of $\beta_{0}$ implies that countries with higher bond market capitalization experience larger increase in interest rate due to a bond volatility shock. We use both public and private bond market cap- 
(a) GDP

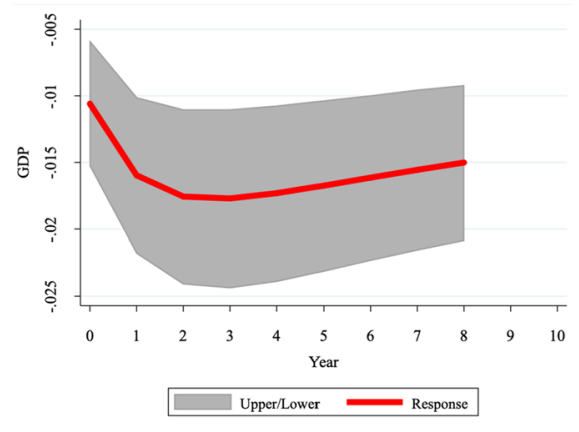

(c) IR

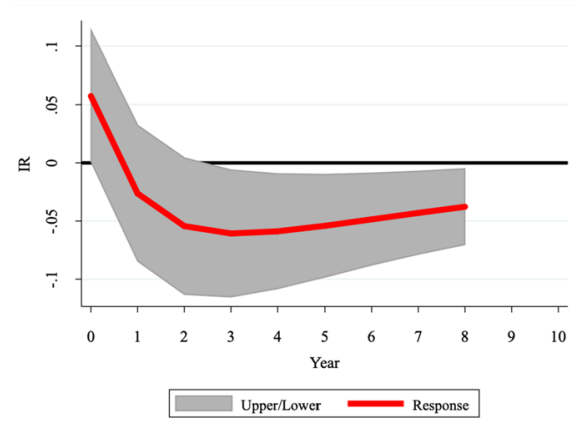

(b) $\mathrm{CPI}$

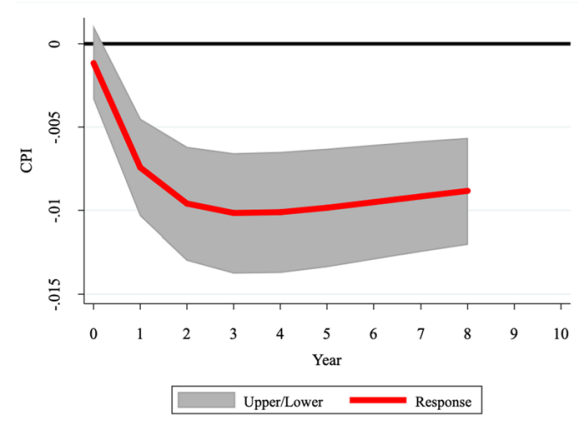

(d) $\mathrm{ER}$

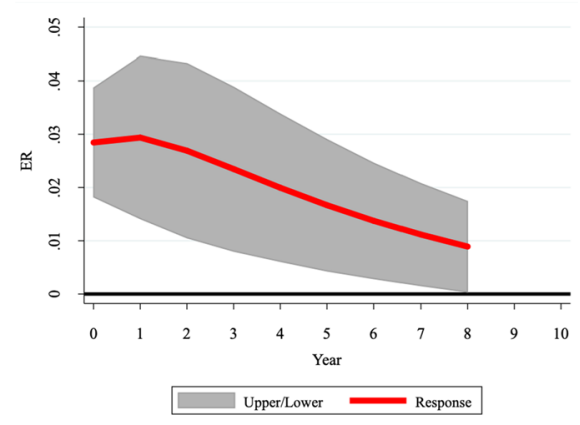

Fig. 4 Response of model variables to VIX shock. Shaded region is $68 \%$ confidence band for the same. These are responses obtained from Panel VAR with country fixed effects

italization alternatively. Similarly, we estimate another model with current account balance $(\mathrm{CAB})$ of the included countries.

$$
\begin{aligned}
I R_{i t+s}= & \theta_{i}^{s}+\beta_{0}^{s} U_{i t} \times C A B+\phi_{0}^{s} U_{i t}+\phi_{1}^{s} U_{i t-1}+\phi_{2}^{s} E R_{i t-1}+\phi_{3}^{s} I R_{i t-1} \\
& +\phi_{4}^{s} G D P_{i t-1}+\phi_{4}^{s} C P I_{i t-1}+e_{i t}
\end{aligned}
$$

Again, the coefficient of interest is $\beta_{0}$. Negative value of $\beta_{0}$ implies that countries with higher current account balance tend to experience smaller increase in their interest rate due to a bond volatility shock.

\section{Empirical results}

In this section, we report and discuss the main empirical results which emerge from our empirical analysis.

\subsection{Country specific VAR}

Figures 15 and 16 in the Appendix present the impact of bond volatility shock on output, interest rate, exchange rate and prices. In Table 1 we present the direction of movement in these 
(a) GDP

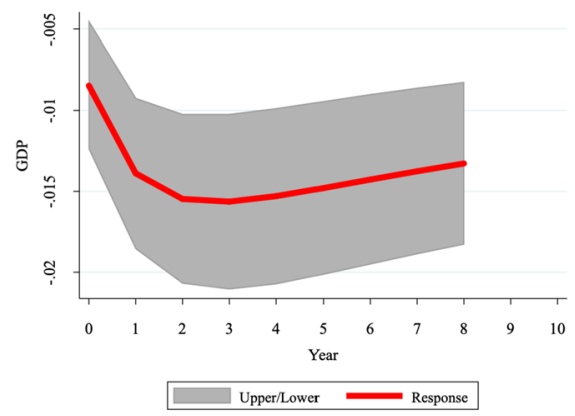

(c) IR

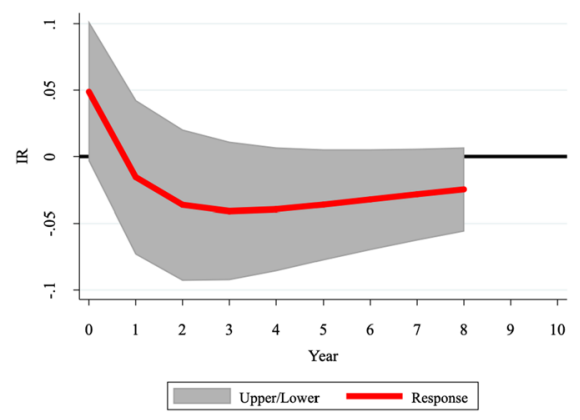

(b) $\mathrm{CPI}$

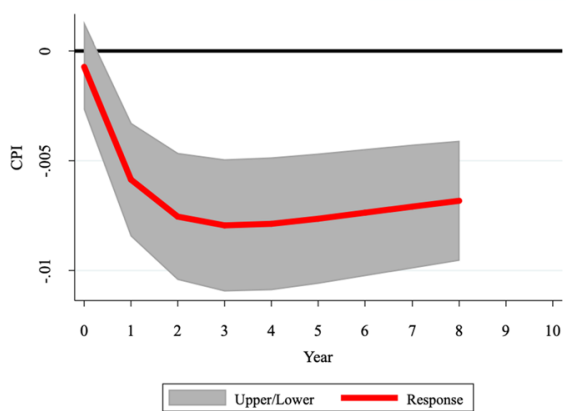

(d) ER

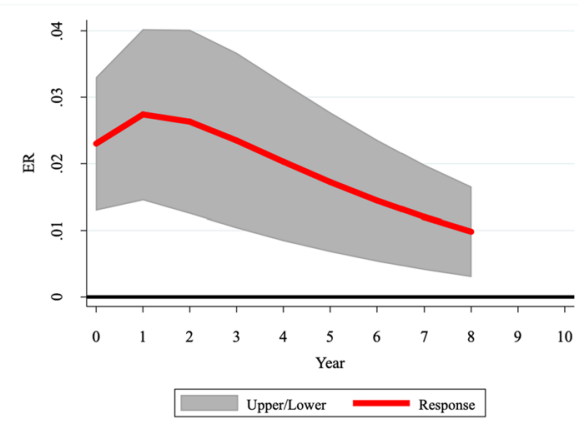

Fig. 5 Response of model variables to VXO shock-Shaded region is $68 \%$ confidence band for the same. These are responses obtained from Panel VAR with country fixed effects

four variables because of a bond volatility shock. If the response is not significant then we leave it blank, and we only report the sign effects which show a significant response. Exchange rate depreciates in four countries, appreciates in Hong Kong and the effect is not significant in other countries. Interest rate declines in 5 countries and increases in three countries. Also, the magnitude of increase in interest rate is in general higher than the magnitude of decrease in interest rate. Output either declines or does not move significantly. Similarly, inflation either declines or does not move significantly except in Malaysia.

Figures 17 and 18 in the Appendix present the impact of VIX shock on output, interest rate, exchange rate and prices. In Table 2 we present the direction of movement in these four variables due to a VIX shock. Exchange rate depreciates in two countries and appreciates in two countries, whereas interest rate declines in 5 countries and increases in two countries. Output either declines or does not move significantly except in Japan. Similarly, inflation either declines or does not move significantly except in Korea and Japan.

Figures 19 and 20 in the Appendix present the impacts of VIX shock on output, interest rate, exchange rate and prices. In Tables 3, 4 we present the direction of movement in these four variables due to VXO. Exchange rate depreciates in three countries and appreciates in two countries. Interest rate declines in 5 countries and increases in two countries. Output either declines or does not move significantly except in Japan; similarly inflation either declines or does not move significantly except in Korea and Japan. The responses due to VXO shock are very similar to responses due to VIX reported above. 
(a) GDP

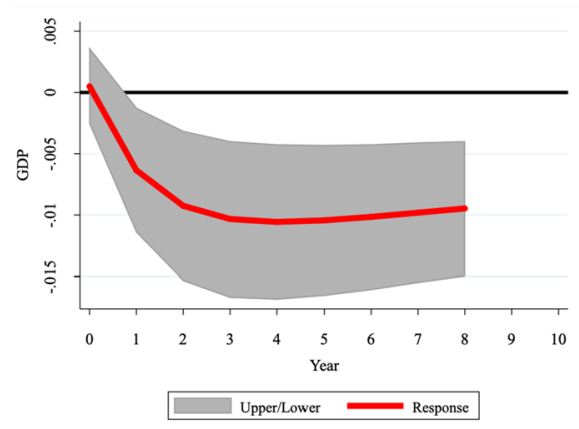

(c) IR

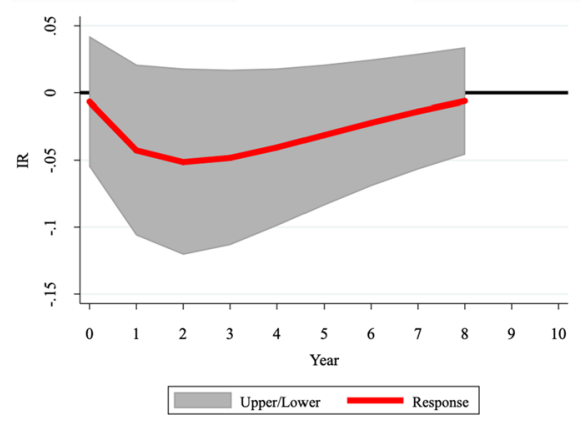

(b) $\mathrm{CPI}$

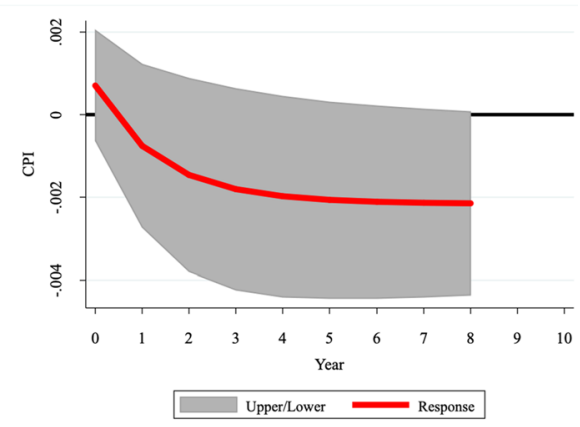

(d) $\mathrm{ER}$

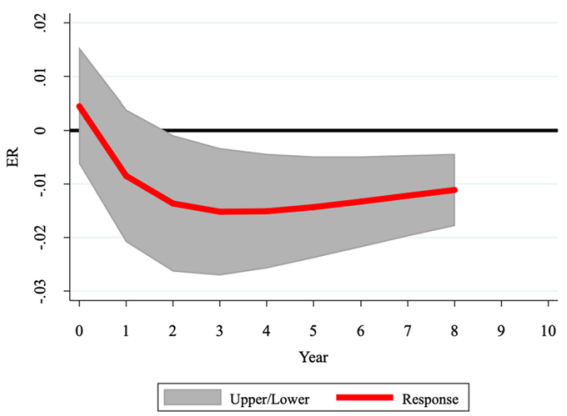

Fig. 6 Response of model variables to EPU shock-Shaded region is $68 \%$ confidence band for the same. These are responses obtained from Panel VAR with country fixed effects

Figure 21 in the Appendix presents the impacts of EPU shock on output, interest rate, exchange rate and prices. In Table 3 we present the direction of movement in these four variables due to a VXO shock. Exchange rate depreciates in two countries and appreciates in one country. Interest rate declines in all countries except China. Output declines in Japan and Hong Kong and increases in Korea, whereas inflation either declines or does not move significantly.

Our Country specific VAR does suffer from country specific heterogeneity and therefore these mixed results are quite expected. Also, these country specific VARs are estimated with small samples. These results are therefore further investigated in a panel VAR analysis in the next sub-section to extract a common response across these countries. An average outcome for this group of countries would obviously depend on the magnitude of a particular sign effect across countries. For such a Panel analysis, which enables controlling for country level heterogeneity with fixed effects, we try to uncover some general pattern, making the analysis useful for policy making.

\subsection{Panel VAR}

Figure 3 gives the response of model variables due to bond volatility (interest rate uncertainty) shock. Interest rate uncertainty shock increases interest rate and depreciates exchange rate. The increase in interest rate is quite persistent and lasts up to 8 years. Interest rate uncertainty 
(a) Bond Volatility Shock

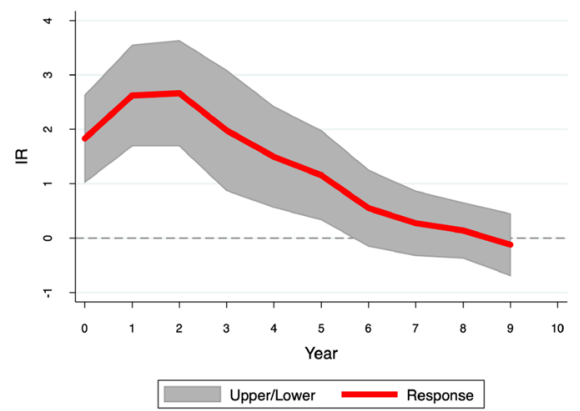

(c) VXO Shock

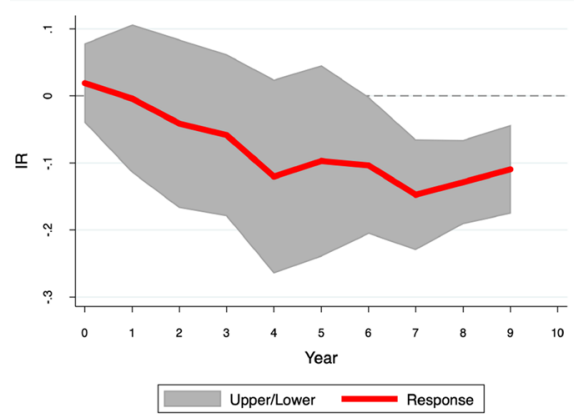

(b) VIX Shock

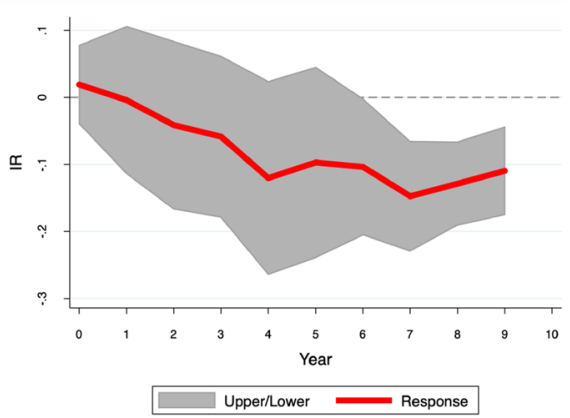

(d) EPU Shock

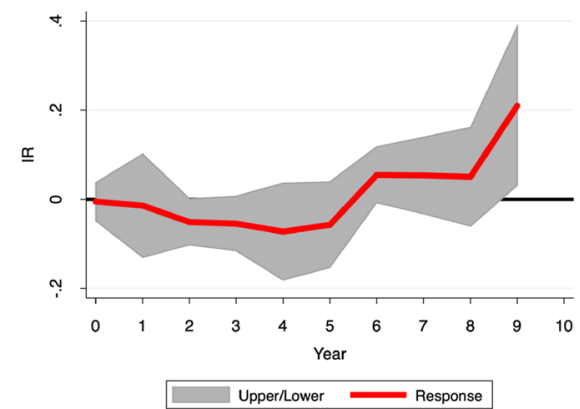

Fig. 7 Response of interest rate to uncertainty shocks and the shaded region is $68 \%$ confidence band for the same. IR is the lending rate. These responses have been obtained using panel local projection explained in Eq. 16

also decreases output and inflation in the medium run, suggesting that it behaves like a demand shock.

Figure 4 gives the response of model variables due to a VIX shock. VIX shock decreases interest rate and depreciates exchange rate. The decrease in interest rate is significant beyond the third year. VIX shock also decreases output and inflation, suggesting that it behaves like a demand shock in the medium run. Decrease in interest rate is followed by decrease in inflation, suggesting that interest rate responds to declining inflation.

Figure 5 gives the response of model variables due to a VXO shock. VXO shock decreases interest rate and depreciates exchange rate. The effect is very similar to the effect due to a VIX shock except that the interest rate does not turn out to be significant. The VXO shock also decreases output. Inflation declines from first period onwards which is similar to a VIX shock. We can say that these two shocks have very similar transmission in the economy as expected, since these two shocks are highly correlated.

Figure 6 gives the response of model variables due to an EPU shock. The response of exchange rate is different in comparison to the response due to bond volatility, VIX and VXO shocks. EPU shock decreases interest rate and appreciates exchange rate. The decrease in interest rate is not significant. EPU shock also decreases output and inflation, but again the effect on inflation is not significant.

Based on these responses, we can say that EPU shock behaves as a demand shock in the short run. The main take away from comparative responses of these four shocks is that 
(a) Bond Volatility Shock

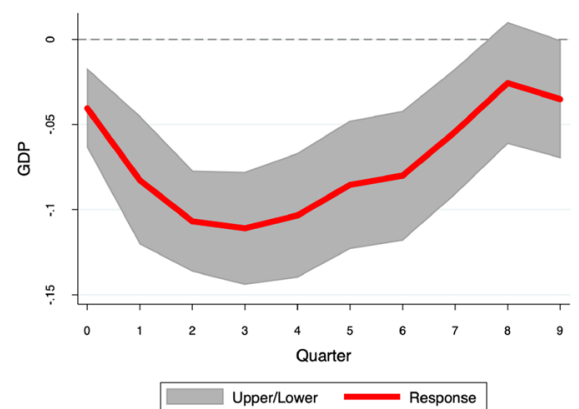

(c) VXO Shock

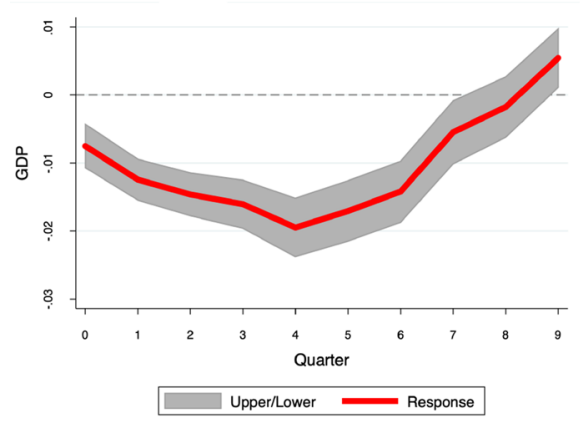

(b) VIX Shock

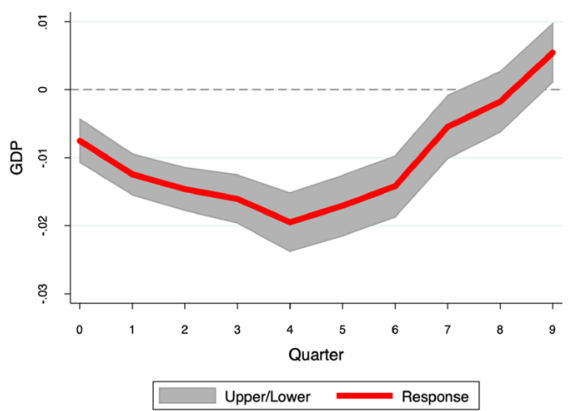

(d) EPU Shock

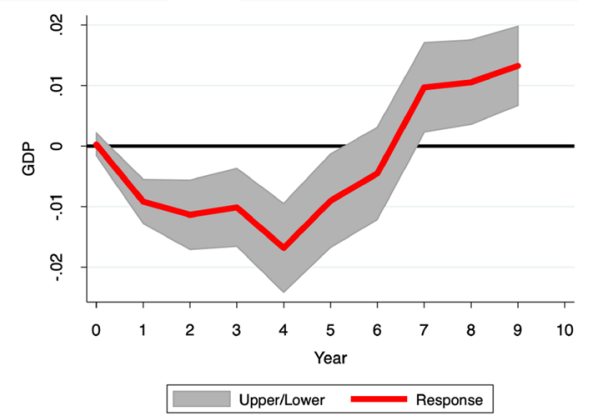

Fig. 8 Response of GDP to uncertainty shocks and the shaded region is $68 \%$ confidence band for the same.These responses have been obtained using panel local projection explained in Eq. 16

the interest rate uncertainty shock and the other three shocks (VIX, VXO, EPU) behave as a demand shock. Also interest rate uncertainty shock increases interest rate which is quite persistent, whereas the other three shocks decrease interest rate. In the latter sub-section, we explore what are the possible channels through which the bond volatility or interest rate uncertainty shock increases interest rate.

Figure 22 in the Appendix gives the responses due to bond volatility shock from the model in which we replace lending rate with monetary policy rate. We find that monetary policy rate increases on impact but significantly declines subsequently. Figure 23 in the Appendix gives the responses due to a bond volatility shock from the model in which we keep both the monetary policy rate and lending rate. We again find that the lending rate increases with a persistent effect. The response of monetary policy rate is very similar to Fig. 22 in the Appendix.

\subsection{Panel local projection}

Figure 7 gives the response of interest rate i.e. lending rate due to these four shocks. These responses are obtained using local projection regression as explained in the empirical framework section. As we can see, apart from the interest rate uncertainty shock, all other shocks lead to a decline in the interest rate. Although the effect is not significant in the case of VIX and VXO in the short run, it becomes significant in the medium run, and the effect due to EPU 
(a) Bond Volatility Shock

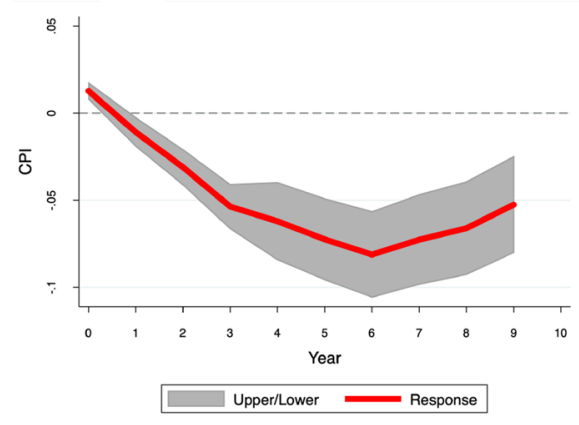

(c) VXO Shock

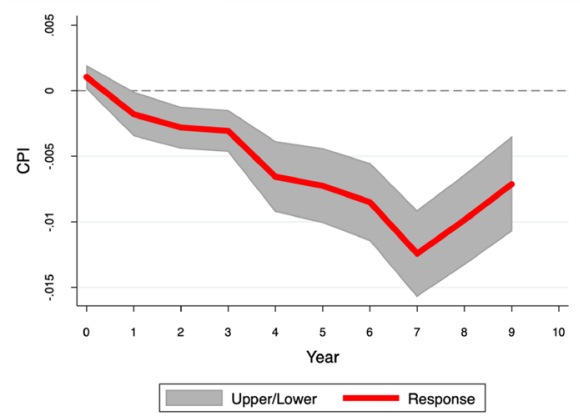

(b) VIX Shock

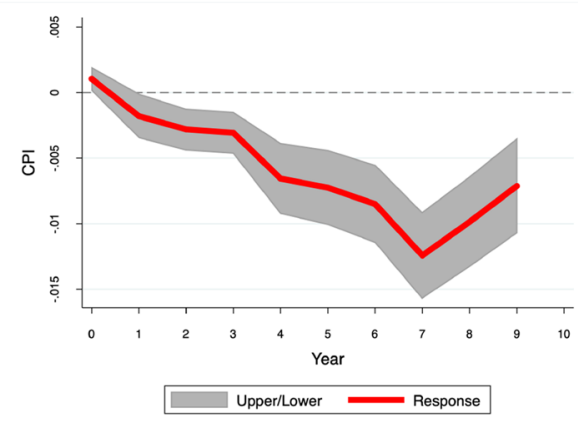

(d) EPU Shock

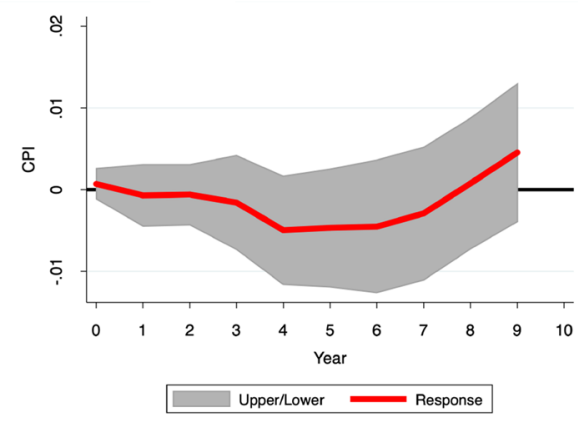

Fig. 9 Response of CPI to uncertainty shocks-the shaded region is $68 \%$ confidence band for the same. These responses have been obtained using panel local projection explained in Eq. 16

is not significant (similar response was obtained using panel VAR earlier). Our conclusion from panel VAR holds as the response of interest rate due to interest rate uncertainty shock is positive, quite large and persistent.

Figure 8 gives the response of output due to these four shocks. As we can see, all four uncertainty shocks lead to decline in output. The negative effect of interest rate uncertainty shock is more persistent in comparison to other shocks. Also, we see output increasing after 6 quarters due to the EPU shock.

Figure 9 gives the response of CPI due to these three shocks. Except EPU, all other three shocks have significant impact on inflation. Response of inflation through local projection is very similar to response of inflation from panel VAR responses.

Figure 10 gives the response of exchange rate due to these four shocks. Except EPU, all other three shocks lead to depreciation in the short run which is similar to the response obtained through panel VAR. In the medium run, these three shocks lead to appreciation of exchange rate which is not the case with panel VAR. Exchange rate appreciates due to EPU shock which is similar to the response obtained from panel VAR. Broadly, the responses obtained from panel local projections are in line with the responses obtained using panel VAR. These responses from panel local projection also substantiate our claim that the response of interest rate (lending rate) is different due to bond volatility shock compared to the other three shocks. 
(a) Bond Volatility Shock

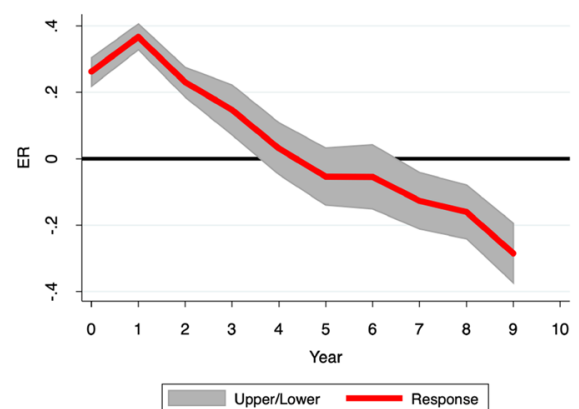

(c) VXO Shock

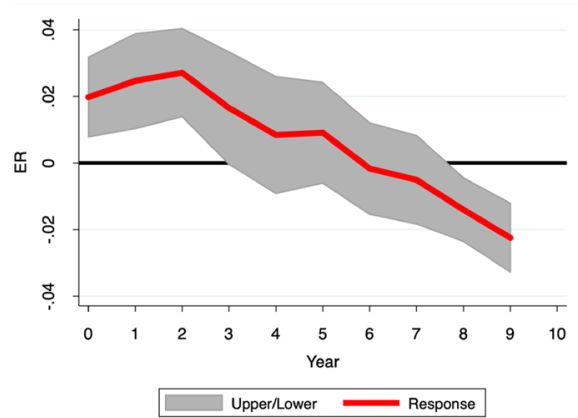

(b) VIX Shock

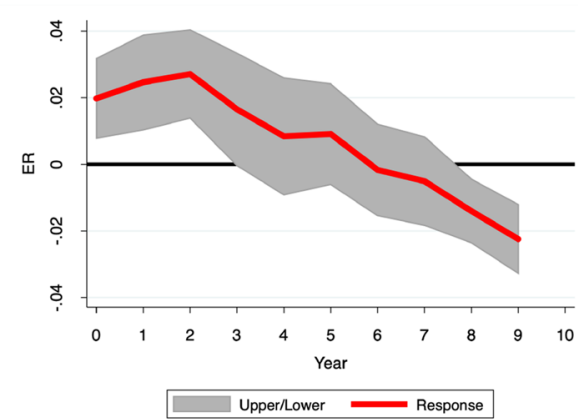

(d) EPU Shock

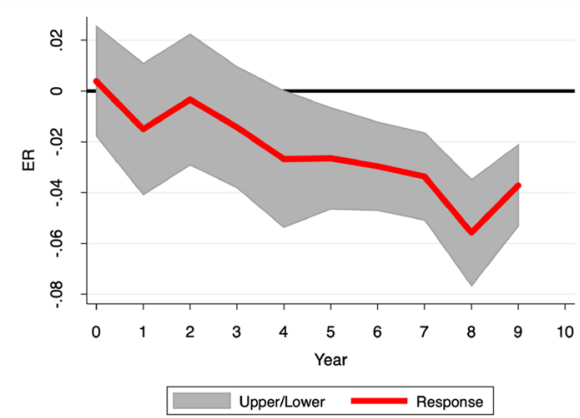

Fig. 10 Response of ER to uncertainty shocks-the shaded region is $68 \%$ confidence band for the same. These responses have been obtained using panel local projection explained in Eq. 16

Figure 24 in the Appendix gives the responses of monetary policy rate due to three shocks (bond volatility, VIX, and VXO). We see that monetary policy rate declines, and these effects are very similar to the effect on monetary policy rate obtained due to a bond volatility shock using panel VAR. This difference is due to the fact that any risk premium due to the interest rate uncertainty gets factored in for the lending rate in responding to the uncertainty, as opposed to the risk-free policy rate.

\subsection{Why bond volatility is different?}

From the discussion in previous sections, it is clear that bond market volatility has significantly different impact on interest rate than other measures of uncertainties considered in this paper. The bond volatility is for 10 year local currency government bond and captures risk arising from uncertainty in interest rate. Increase in volatility makes it difficult to forecast interest rate and therefore the shock associated with bond volatility can be viewed as interest rate uncertainty shock. We argue that the effect of this interest rate uncertainty on the interest rate should be higher in countries having large public bond market capitalization. To test this hypothesis, we introduce an interaction of bond volatility and size of public bond market capitalisation and estimate the coefficient associated with this interaction for $t=0,1,2,3$. We estimate the responses at lower horizon because of small sample with annual data. Figure 


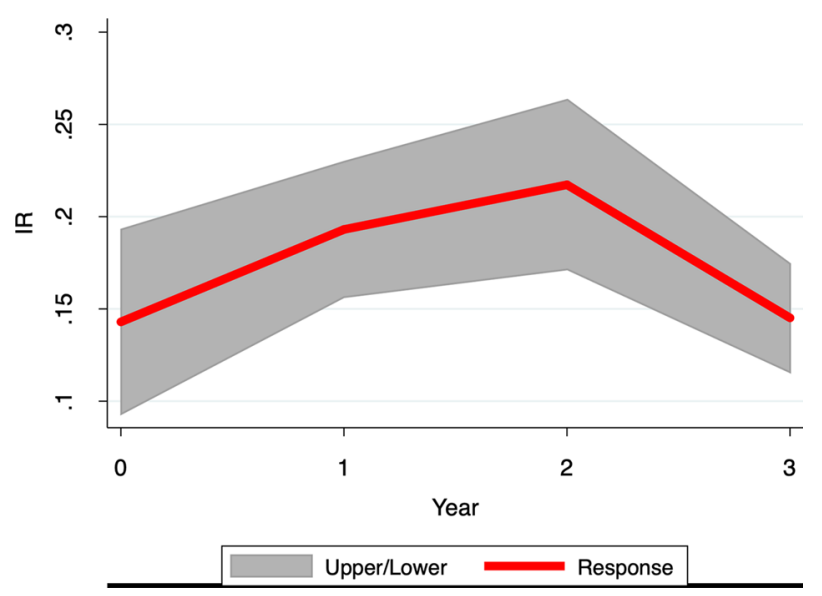

Fig. 11 Coefficient of the interaction of bond volatility shock with public bond market capitalization. These coefficients have been obtained using panel local projection explained in Eq. 17

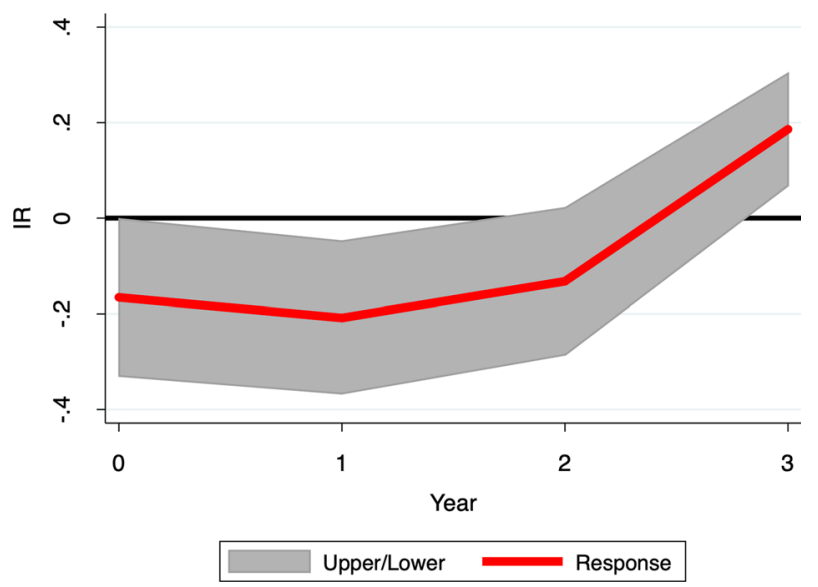

Fig. 12 Coefficient of the interaction of bond volatility shock with private bond market capitalization. These coefficients have been obtained using panel local projection explained in Eq. 17

11 gives these coefficients with their standard error. We find that larger public bond market capitalisation leads to more pronounced effect of bond volatility shock on interest rate.

Figure 12 gives these coefficients for private bond market capitalisation. We do not find significant effect of the private bond market capitalization on transmission of bond volatility shock on interest rate. It is negative and insignificant on impact, which becomes marginally significant after a year and then becomes insignificant again before turning positive and significant in the 3 rd year as before.

Higher public bond market capitalisation is likely to be driven by higher fiscal deficit in these countries. We also explore the role of current account balance in influencing the transmission of bond volatility shock to interest rate. Figures 13 gives the coefficient associated with the interaction of bond volatility shock and current account balance. The coefficient is negative and significant, suggesting that higher current account balance significantly diminishes the pass through of bond volatility shock to interest rate. Therefore, we can say that 


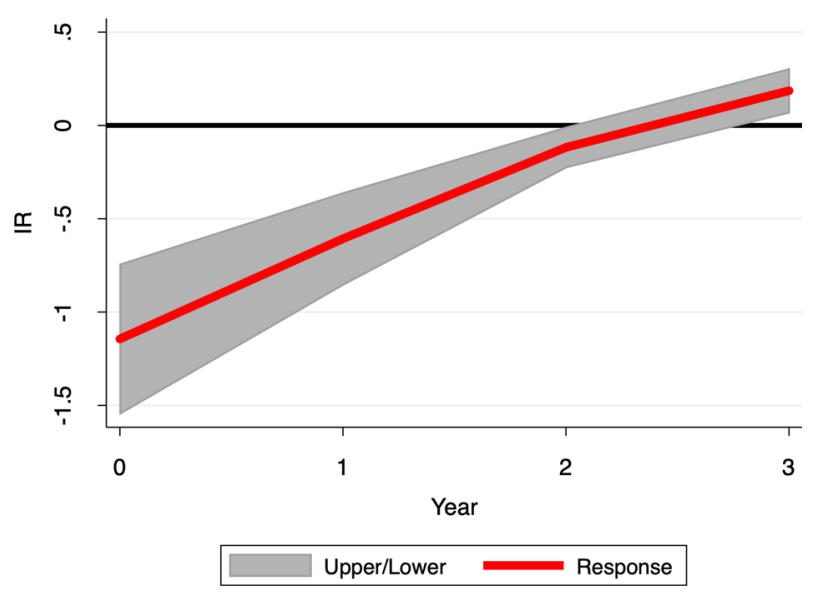

Fig. 13 Coefficient of the interaction of bond volatility shock with current account balance. These coefficients have been obtained using panel local projection explained in Eq. 18

both fiscal balance and current account balance influence the transmission of bond volatility shock to interest rate, and countries having higher fiscal deficit and current account deficit are more severely affected due to interest rate uncertainty shock.

We find that countries with worse capital account experience sharper increase in lending rate due to bond volatility shock. We repeat our annual exercises with a slightly different setting. We estimate the effect on current account balance due to the three uncertainty shocks and the same is given in Fig. 14. We find that current account worsens due to an increase in bond volatility but improves afterwards. There is a contrast in our results in the sense that while bond market volatility gives rise to a significant decline in current account balance, global uncertainties have no significant effect on the current account balance in the short run. The difference in the results is due to an increase in the interest rate driving capital inflows and creating demand for foreign goods and services in the former case, whereas in the latter case there is no significant change in the interest rate and hence no impact on capital flows, thereby keeping the current account balance unchanged. The latter significant increase in current account balance could also be arising due to a decrease in public spending and an increase in private saving as expected due to the increase in interest rate.

\section{Concluding observations}

Since the global financial crisis (GFC) of 2008, there has been a surge of empirical studies on the effect of financial market uncertainty on the economy. There was a great deal of uncertainty in global financial markets in the build-up to that crisis due to extensive financial innovation, evident in new instruments such as mortgage backed securities (MBS) and collateralized debt obligations (CDO). Uncertainty was further compounded by the failure of regulatory authorities, especially in the U.S. which was the epicenter of the financial innovation as well as the crisis, to keep up with the sheer speed and scale of innovation. The widespread perception that GFC was closely interlinked with financial uncertainty was the catalyst for a large and growing empirical literature. Furthermore, the COVID-19 pandemic, which triggered an unprecedented global public health and economic crisis, is potentially a major source of 
(a) Bond Volatility Shock

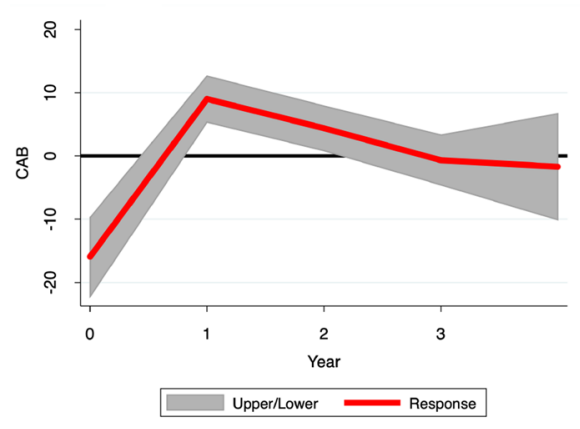

(c) VXO Shock

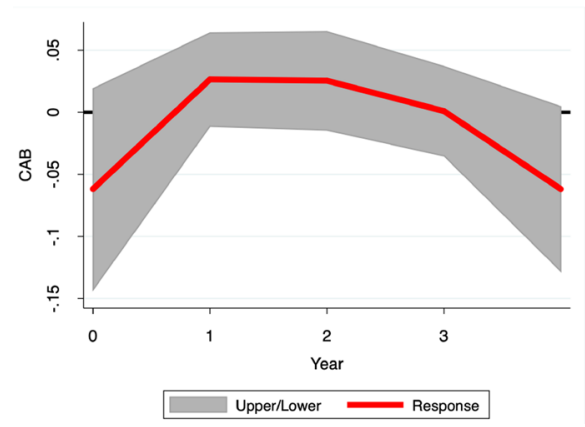

(b) VIX Shock

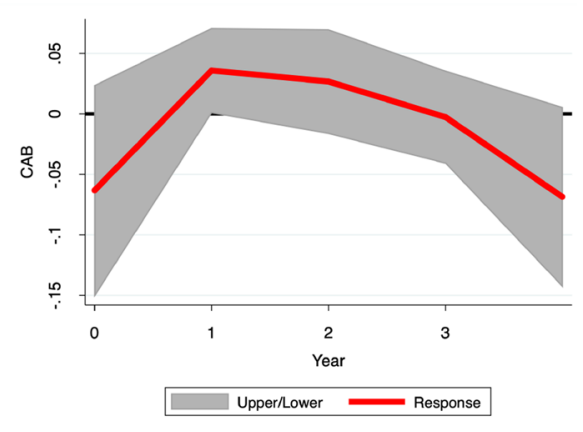

Fig. 14 Response of current account balance due to uncertainty shocks-the shaded region is $68 \%$ confidence band for the same. These responses have been obtained using panel local projection explained in Eq. 16

uncertainty in global financial markets, as evident during the severe market turmoil of early March 2020.

In this paper, we look at the effects of an alternative measure of financial market uncertainty, namely bond market volatility. More specifically, we examine the effects of the volatility of local currency bond markets of emerging East Asian economies, which consist of Japan, China, Korea, and major ASEAN economies of Southeast Asia. Emerging East Asia experienced rapid development of their financial systems in the past few decades. The rapid financial development has substantially closed the gap between the region's dynamic real economies and backward financial sectors. One component that has grown especially rapidly is local currency bond markets, which East Asian policymakers prioritized since the Asian financial crisis of 1997-1998 to protect the region from financial instability. More precisely, local currency bond market was the natural solution to the double mismatch problem-i.e., borrowing short-term in foreign currency to finance investments that generate revenues in the long term-that lay at the heart of the Asian financial crisis. Local currency bond market development has contributed to the region's financial stability since that crisis.

At the same time, volatility in local currency bond markets can reflect and be associated with macroeconomic uncertainty, especially since the region's aggregate market size is now comparable to Europe's markets. More precisely, it is plausible to view bond market volatility shock as interest rate uncertainty shock. The price of bonds is heavily influenced by the interest rate; so we can expect elevated uncertainty about the trajectory of interest rates to create 
volatility in the bond market. Indeed we find that bond volatility is more closely associated with interest rate than other measures of uncertainty pertaining to equity market and economic policy. Most significantly, we find that bond market volatility, which is a measure of interest rate uncertainty, has a more pronounced effect on interest rates in countries with larger government bond markets. The size of the government bond market is likely to be positively associated with the fiscal and current account deficits. Therefore, a plausible interpretation of our results is that bond market volatility has a bigger effect on interest rates in countries with larger fiscal and current account deficits. Finally, while bond market uncertainty is related to interest rate uncertainty, overall bond market development can promote financial stability and provide a stable source of financing for infrastructure and other long-term investments.

\section{Appendix}

\section{A Country specific VAR}

See Figs. 15, 16, 17, 18, 19, 20 and 21.
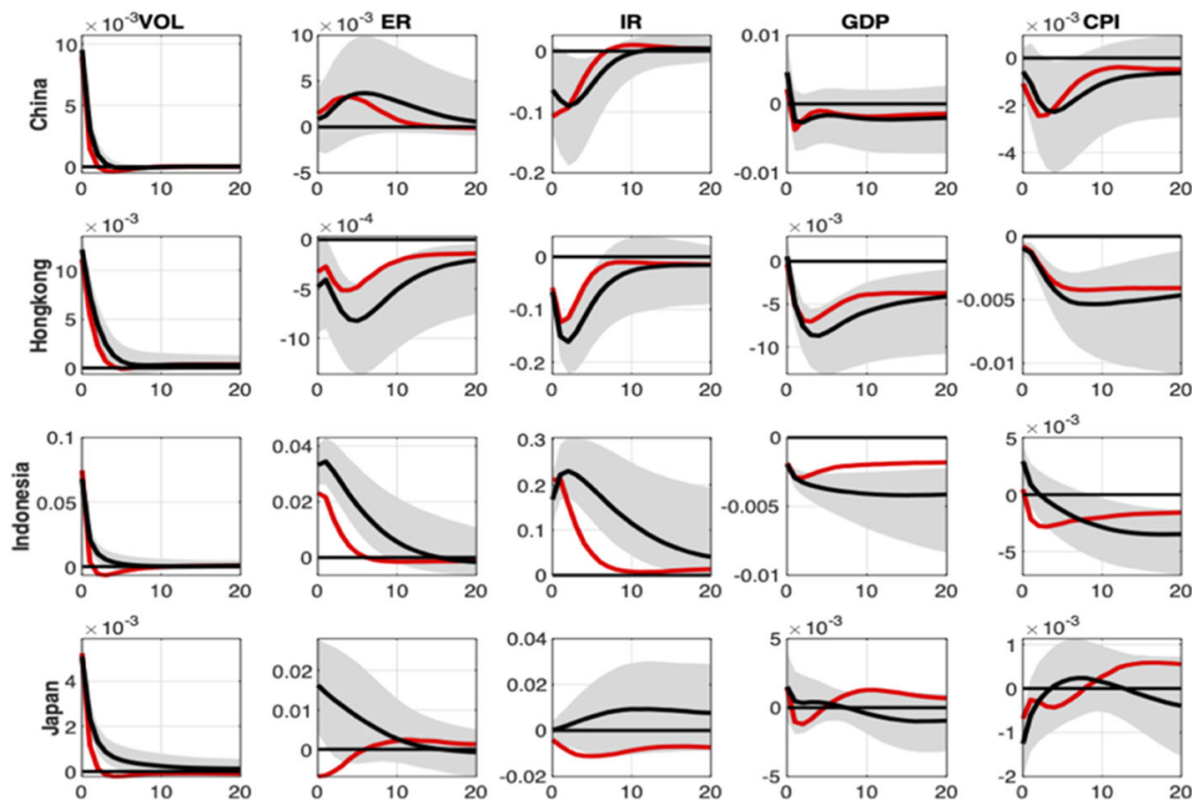

Fig. 15 Response of model variables to respective bond market volatility shock across countries. Black line is the response due to shock identified using penalty function method and the shaded region is $68 \%$ confidence band for the same. Red line is the response due to the shock being identified by using Cholesky method 

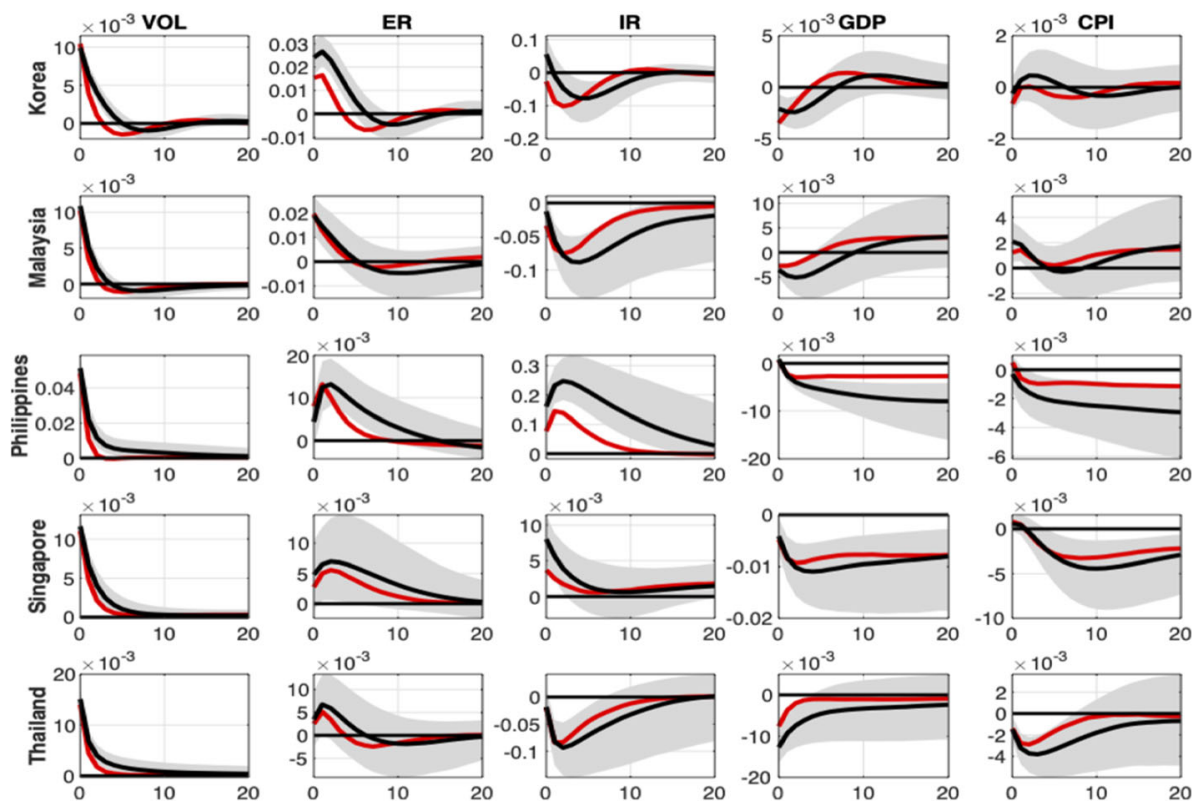

Fig. 16 Response of model variables to respective bond market volatility shock across countries. Black line is the response due to the shock being identified using penalty function method and the shaded region is $68 \%$ confidence band for the same. Red line is the response due to the shock being identified by using Cholesky method
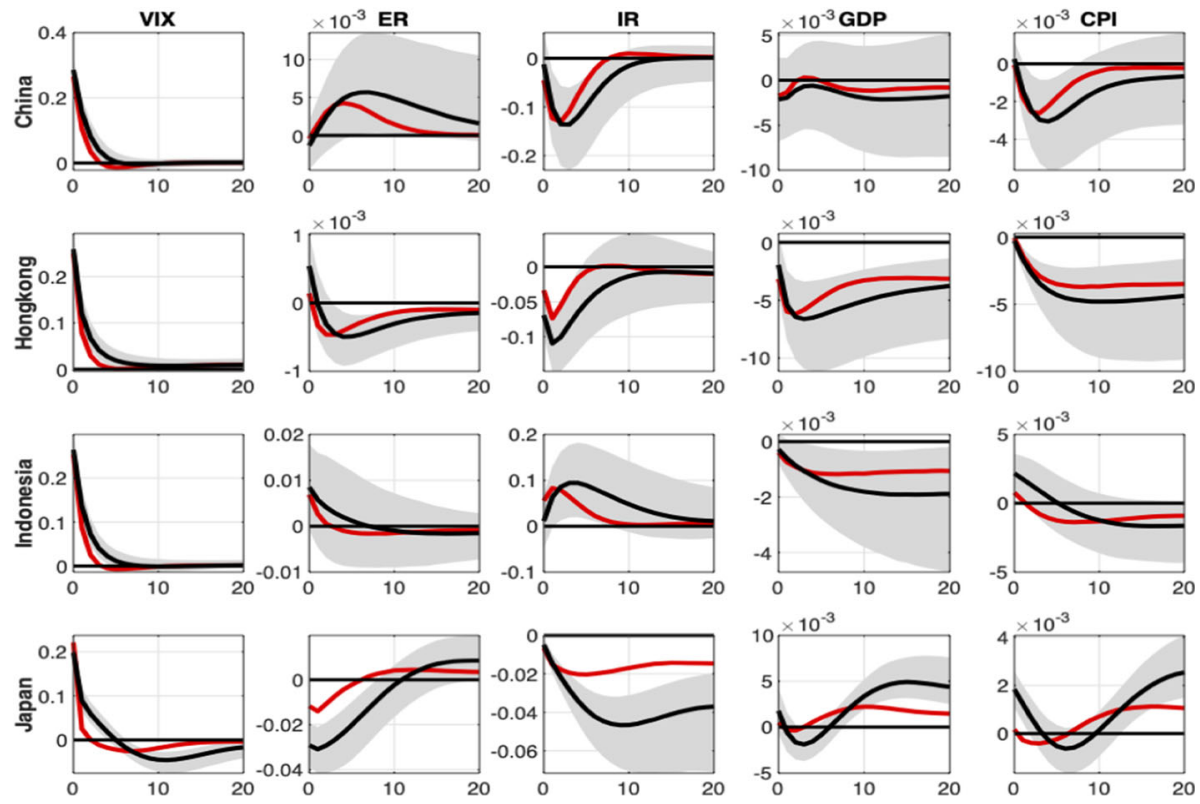

Fig. 17 Response of model variables to VIX shock across countries. Black line is response due to shock identified using penalty function method, and the shaded region is $68 \%$ confidence band for the same. Red line is response due to the shock being identified by using Cholesky method 

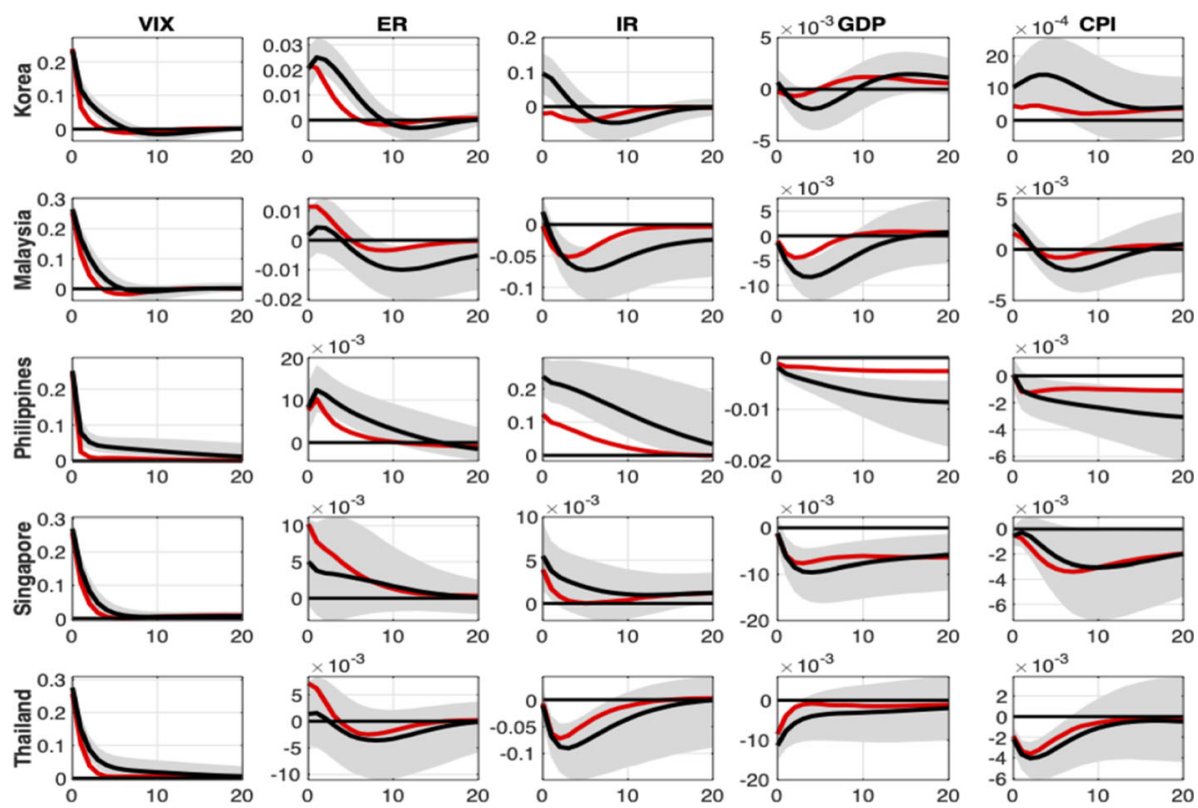

Fig. 18 Response of model variables to VIX shock across countries. Black line is response due to shock identified using penalty function method and the shaded region is $68 \%$ confidence band for the same. Red line refers to the response due to the shock identified by using Cholesky method
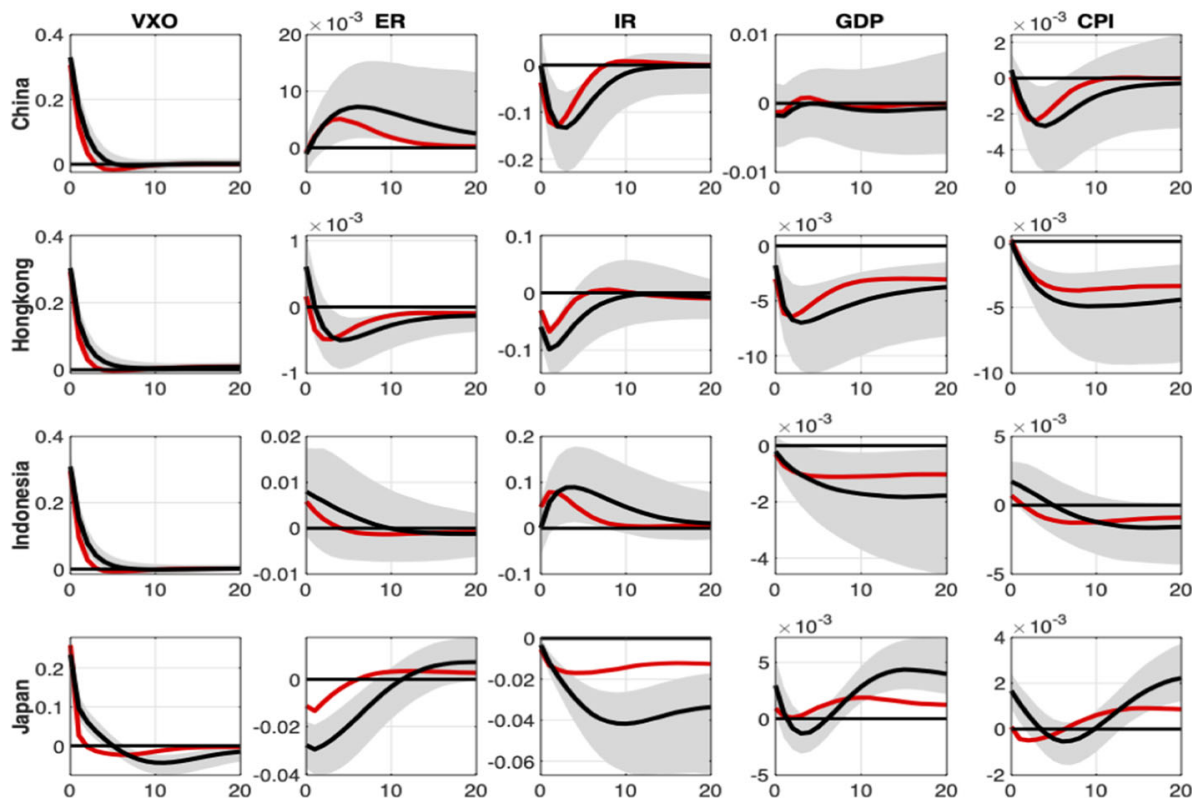

Fig. 19 Response of model variables to VXO shock across countries. Black line is response due to shock identified using penalty function method and the shaded region is $68 \%$ confidence band for the same. Red line shows the response due to the shock identified by using Cholesky method 

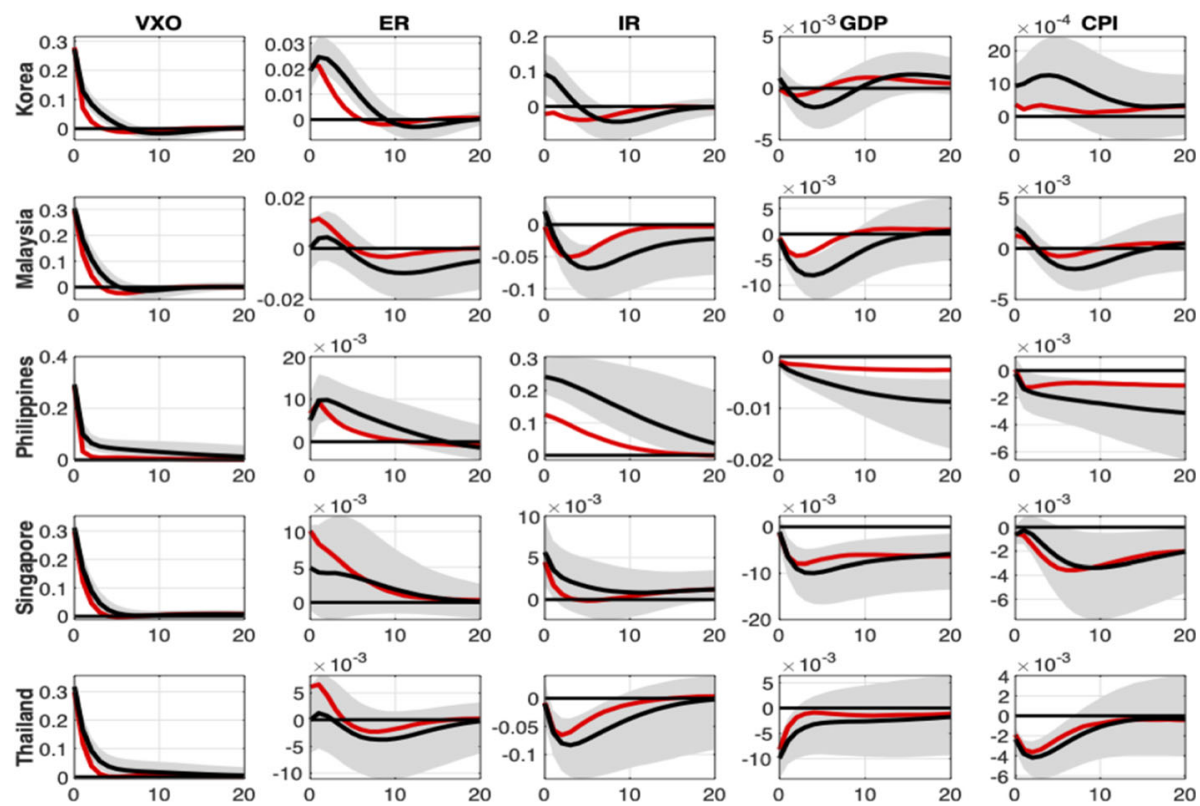

Fig. 20 Response of model variables to VXO shock across countries. Black line is response due to shock identified using penalty function method and the shaded region is $68 \%$ confidence band for the same. Red line is the response due to the shock being identified by using Cholesky method
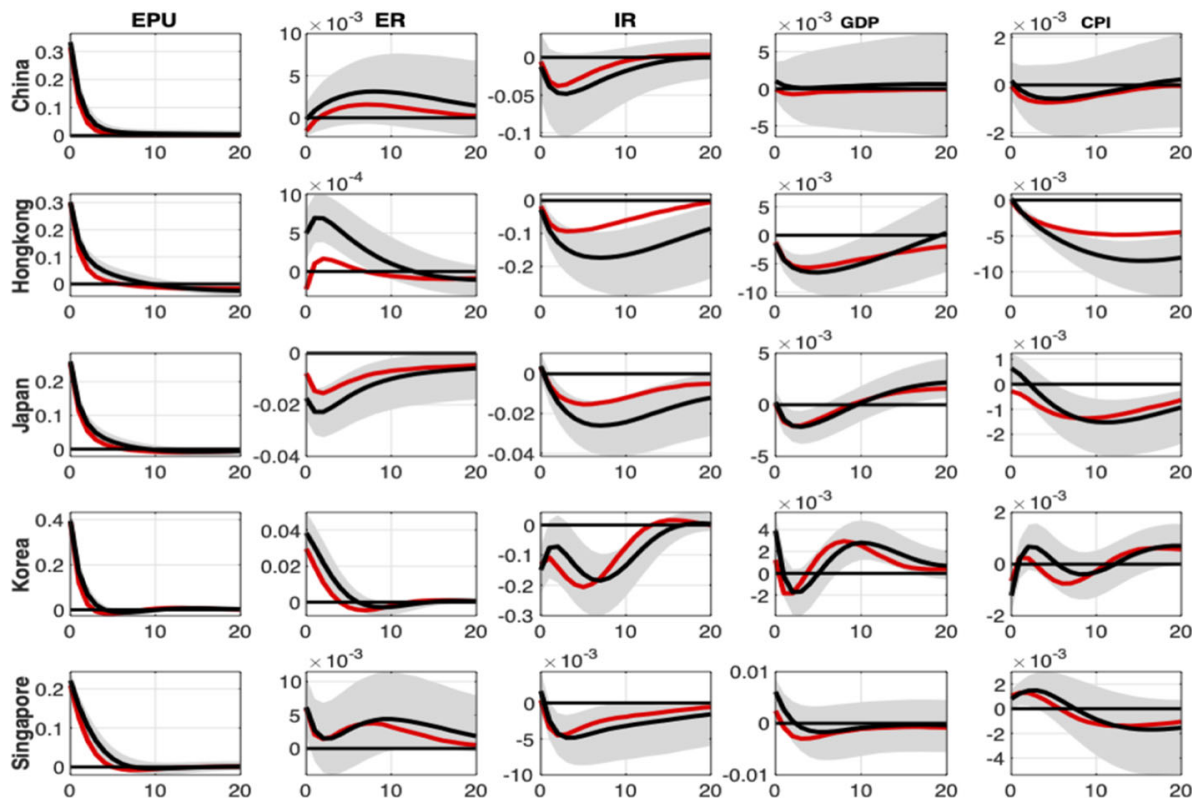

Fig. 21 Response of model variables to economic policy uncertainty shock across countries. Black line is response due to shock identified using penalty function method and the shaded region is $68 \%$ confidence band for the same. Red line shows the response due to the shock being identified by using Cholesky method 


\section{B Panel VAR}

See Figs. 22, 23 and 24.

(a) GDP

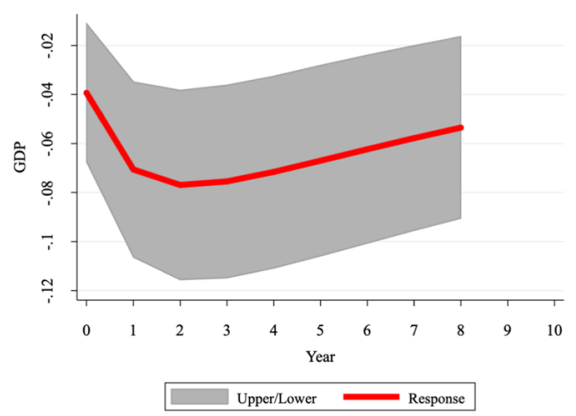

(c) IR

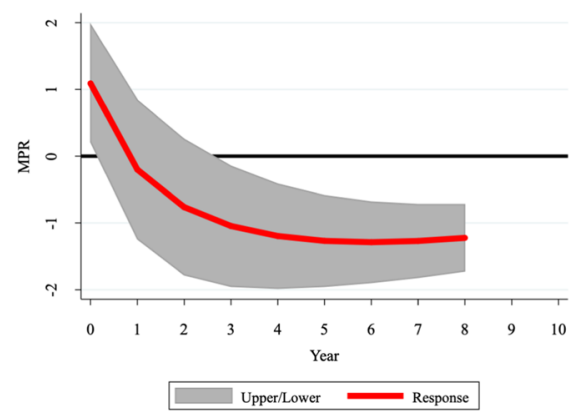

(b) $\mathrm{CPI}$

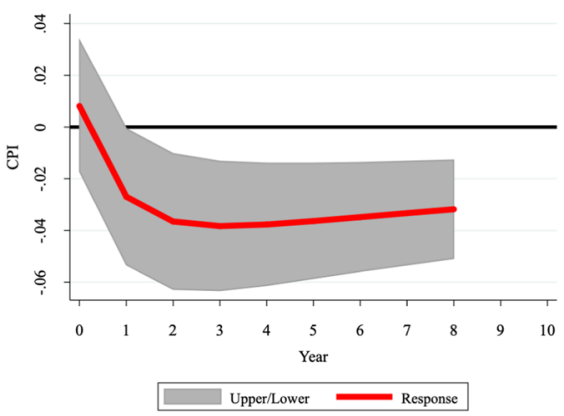

(b) $\mathrm{ER}$

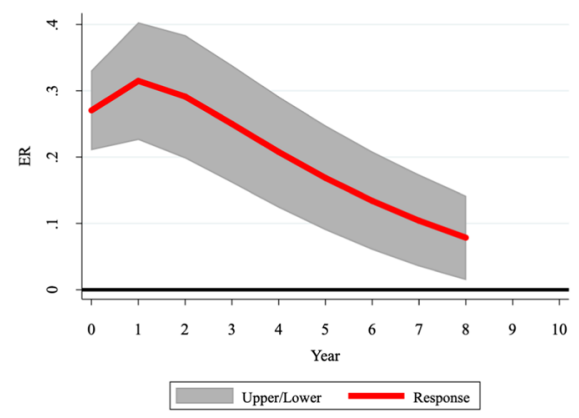

Fig. 22 Response of model variables to bond volatility shock. IR is monetary policy rate. Shaded region is $68 \%$ confidence band for the same. These responses have been obtained using panel VAR with country fixed effects 
(a) GDP

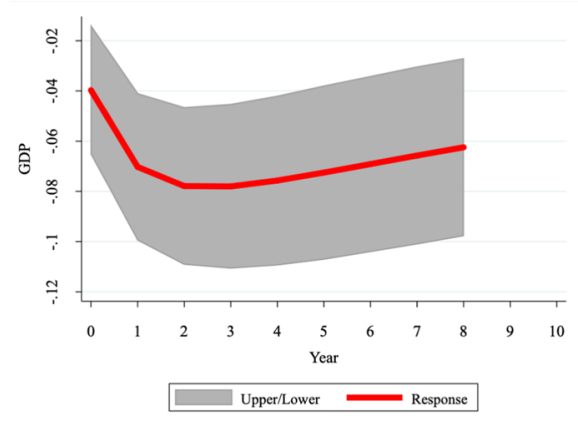

(c) IR

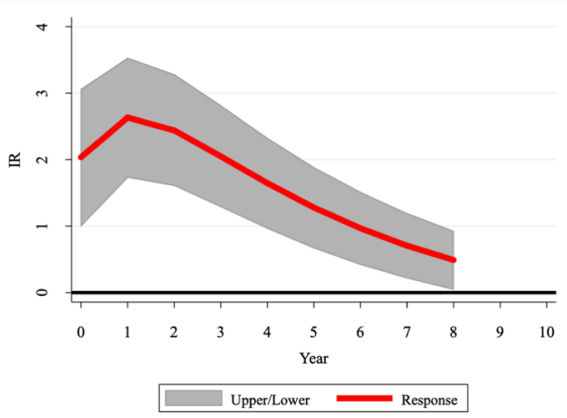

(b) $\mathrm{CPI}$

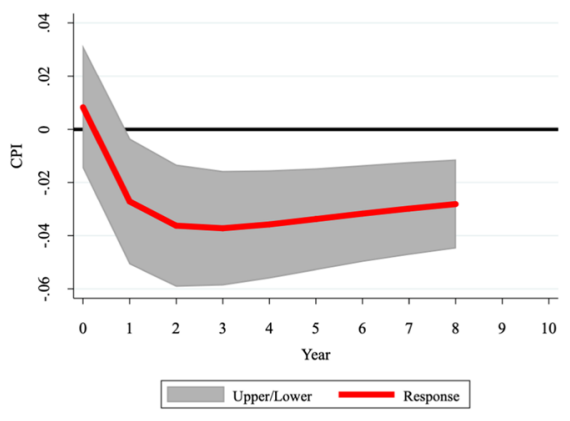

(d) MPR

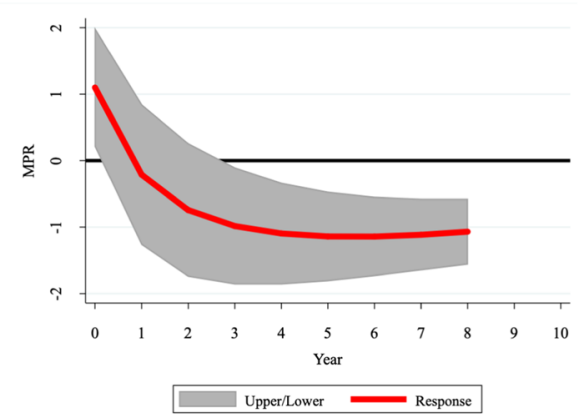

Fig. 23 Response of model variables to bond volatility shock. MPR is monetary policy rate and IR is lending rate. Shaded region is $68 \%$ confidence band for the same. These responses have been obtained using panel VAR with country fixed effects 


\section{B.1 Panel local projection}

(a) Bond Volatility Shock

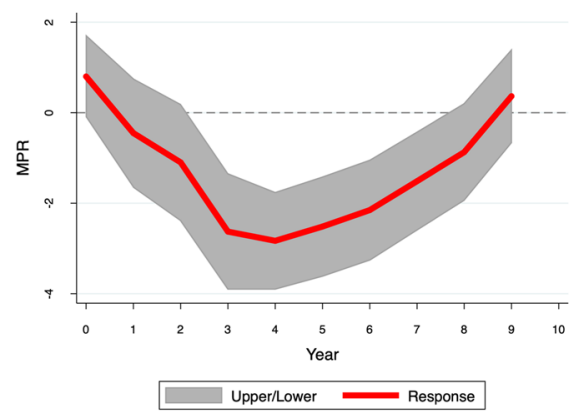

(c) VXO Shock

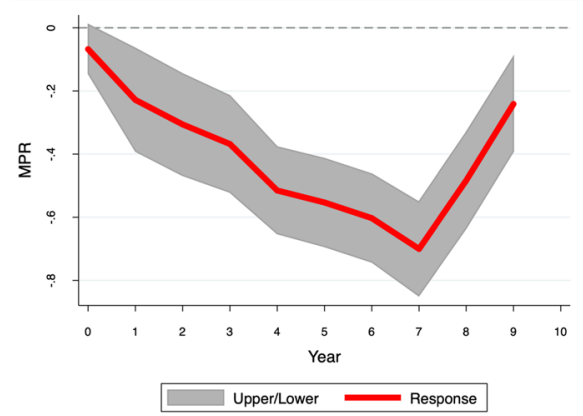

(b) VIX Shock

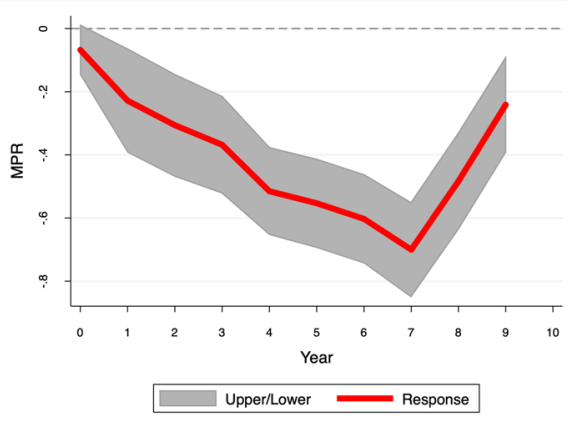

Fig. 24 Response of monetary policy rate due to uncertainty shocks-the shaded region is $68 \%$ confidence band for the same. These responses have been obtained using panel local projection explained in Eq. 16 


\section{Summary statistics}

See Table 5.

Table 5 Summary statistics

\begin{tabular}{|c|c|c|c|c|c|c|}
\hline & & Obs & Mean & $\mathrm{SD}$ & Min & Max \\
\hline \multirow[t]{2}{*}{$\mathrm{CHN}$} & ER & 54.00 & 6.70 & 0.48 & 6.10 & 8.00 \\
\hline & IR & 54.00 & 5.53 & 0.98 & 4.35 & 7.47 \\
\hline \multirow[t]{3}{*}{ HKG } & ER & 55.00 & 7.78 & 0.03 & 7.75 & 7.85 \\
\hline & IR & 55.00 & 5.43 & 0.97 & 5.00 & 8.00 \\
\hline & MPR & 47.00 & 1.34 & 1.57 & 0.50 & 6.75 \\
\hline \multirow[t]{3}{*}{ IDN } & ER & 55.00 & 11186.89 & 2127.31 & 8597.00 & 14929.00 \\
\hline & IR & 55.00 & 12.63 & 1.54 & 10.35 & 16.34 \\
\hline & MPR & 47.00 & 6.63 & 1.27 & 4.25 & 9.25 \\
\hline \multirow[t]{2}{*}{ JPN } & ER & 55.00 & 103.09 & 13.80 & 76.63 & 123.23 \\
\hline & IR & 55.00 & 1.39 & 0.32 & 0.99 & 1.94 \\
\hline \multirow[t]{3}{*}{ KOR } & ER & 55.00 & 1105.13 & 93.58 & 915.10 & 1383.50 \\
\hline & IR & 55.00 & 4.92 & 1.25 & 3.24 & 7.40 \\
\hline & MPR & 47.00 & 2.49 & 1.15 & 1.25 & 5.25 \\
\hline \multirow[t]{3}{*}{ MYS } & ER & 52.00 & 3.56 & 0.43 & 3.02 & 4.49 \\
\hline & IR & 52.00 & 5.13 & 0.70 & 4.49 & 6.63 \\
\hline & MPR & 47.00 & 3.01 & 0.40 & 2.00 & 3.50 \\
\hline \multirow[t]{3}{*}{ PHL } & ER & 50.00 & 46.43 & 3.55 & 40.94 & 54.25 \\
\hline & IR & 50.00 & 6.68 & 1.27 & 5.43 & 9.43 \\
\hline & MPR & 47.00 & 4.09 & 0.92 & 3.00 & 7.50 \\
\hline \multirow[t]{3}{*}{ SGP } & ER & 55.00 & 1.37 & 0.10 & 1.22 & 1.62 \\
\hline & IR & 55.00 & 5.35 & 0.04 & 5.25 & 5.38 \\
\hline & MPR & 47.00 & 0.85 & 0.63 & 0.17 & 2.25 \\
\hline \multirow[t]{3}{*}{ THA } & ER & 55.00 & 33.15 & 2.13 & 29.31 & 38.80 \\
\hline & IR & 55.00 & 4.97 & 0.69 & 4.08 & 6.58 \\
\hline & MPR & 47.00 & 2.15 & 0.77 & 1.25 & 3.75 \\
\hline
\end{tabular}

IR is lending rate, MPR is monetary policy rate and ER is bilateral exchange rate (domestic currency per dollar) 


\section{References}

Annicchiarico, B., \& Rossi, L. (2015). Taylor rules, long-run growth and real uncertainty. Economics Letters, $133,31-34$.

Arellano, C., Bai, Y., \& Kehoe, P. J. (2019). Financial frictions and fluctuations in volatility. Journal of Political Economy, 127(5), 2049-2103.

Baker, S. R., Bloom, N., \& Davis, S. J. (2016). Measuring economic policy uncertainty. The Quarterly Journal of Economics, 131(4), 1593-1636.

Barsky, R. B., \& Sims, E. R. (2011). News shocks and business cycles. Journal of Monetary Economics, 58(3), 273-289.

Basu, S., \& Bundick, B. (2017). Uncertainty shocks in a model of effective demand. Econometrica, 85(3), 937-958.

Baum, C. F., Stephan, A., \& Talavera, O. (2009). The effects of uncertainty on the leverage of nonfinancial firms. Economic Inquiry, 47(2), 216-225.

Bernanke, B. S. (1983). Irreversibility, uncertainty, and cyclical investment. The Quarterly Journal of Economics, 98(1), 85-106.

Bhattarai, K., Mallick, S. K., \& Yang, B. (2021). Are global spillovers complementary or competitive? Need for international policy coordination. Journal of International Money and Finance, 110, 102291.

Bloom, N. (2014). Fluctuations in uncertainty. Journal of Economic Perspectives, 28, 153-176.

Bloom, N. (2009). The impact of uncertainty shocks. Econometrica, 77(3), 623-685.

Byrne, J. P., Spaliara, M. E., \& Tsoukas, S. (2016). Firm survival, uncertainty, and financial frictions: Is there a financial uncertainty accelerator? Economic Inquiry, 54(1), 375-390.

Caggiano, G., Castelnuovo, E., \& Groshenny, N. (2014). Uncertainty shocks and unemployment dynamics in U.S. recessions. Journal of Monetary Economics, 67, 78-92.

Caldara, D., Fuentes-Albero, C., Gilchrist, S., \& Zakrajsek, E. (2016). The macroeconomic impact of financial and uncertainty shocks. European Economic Review, 88, 185-207.

Christiano, L. J., Motto, R., \& Rostagno, M. (2014). Risk shocks. American Economic Review, 104(1), 27-65.

Dixit, A. K., Dixit, R. K., \& Pindyck, R. S. (1994). Investment under uncertainty. Princeton University Press.

Fasani, S., \& Rossi, L. (2018). Are uncertainty shocks aggregate demand shocks? Economics Letters, 167, $142-146$.

Faust, J. (1998). The robustness of identified VAR conclusions about money. In Carnegie-Rochester conference series on public policy (Vol. 49, pp. 207-244). North-Holland.

Ghironi, F., \& Ozhan, G. K. (2020). Interest rate uncertainty as a policy tool (Vol. No. w27084). National Bureau of Economic Research.

Gilchrist, S., Sim, J. W., \& Zakrajsek, E. (2014). Uncertainty, financial frictions, and investment dynamics (Vol. No. w20038). National Bureau of Economic Research.

Istiak, K., \& Serletis, A. (2020). Risk, uncertainty, and leverage. Economic Modelling, 91, 257-273.

Holtemoller, O., \& Mallick, S. (2016). Global food prices and monetary policy in an emerging market economy: The case of India. Asian Journal of Economics, 46, 56-70.

Kumar, A., Mallick, S., \& Sinha, A. (2021). Is uncertainty the same everywhere? Advanced versus emerging economies. Economic Modelling, 101, Art.\# 105524.

Kurmann, A., \& Otrok, C. (2013). News shocks and the slope of the term structure of interest rates. American Economic Review, 103(6), 2612-32.

Leduc, S., \& Liu, Z. (2016). Uncertainty shocks are aggregate demand shocks. Journal of Monetary Economics, $82,20-35$.

Mountford, A., \& Uhlig, H. (2009). What are the effects of fiscal policy shocks? Journal of Applied Econometrics, 24(6), 960-992.

Uhlig, H. (2005). What are the effects of monetary policy on output? Results from an agnostic identification procedure. Journal of Monetary Economics, 52(2), 381-419.

Publisher's Note Springer Nature remains neutral with regard to jurisdictional claims in published maps and institutional affiliations. 